
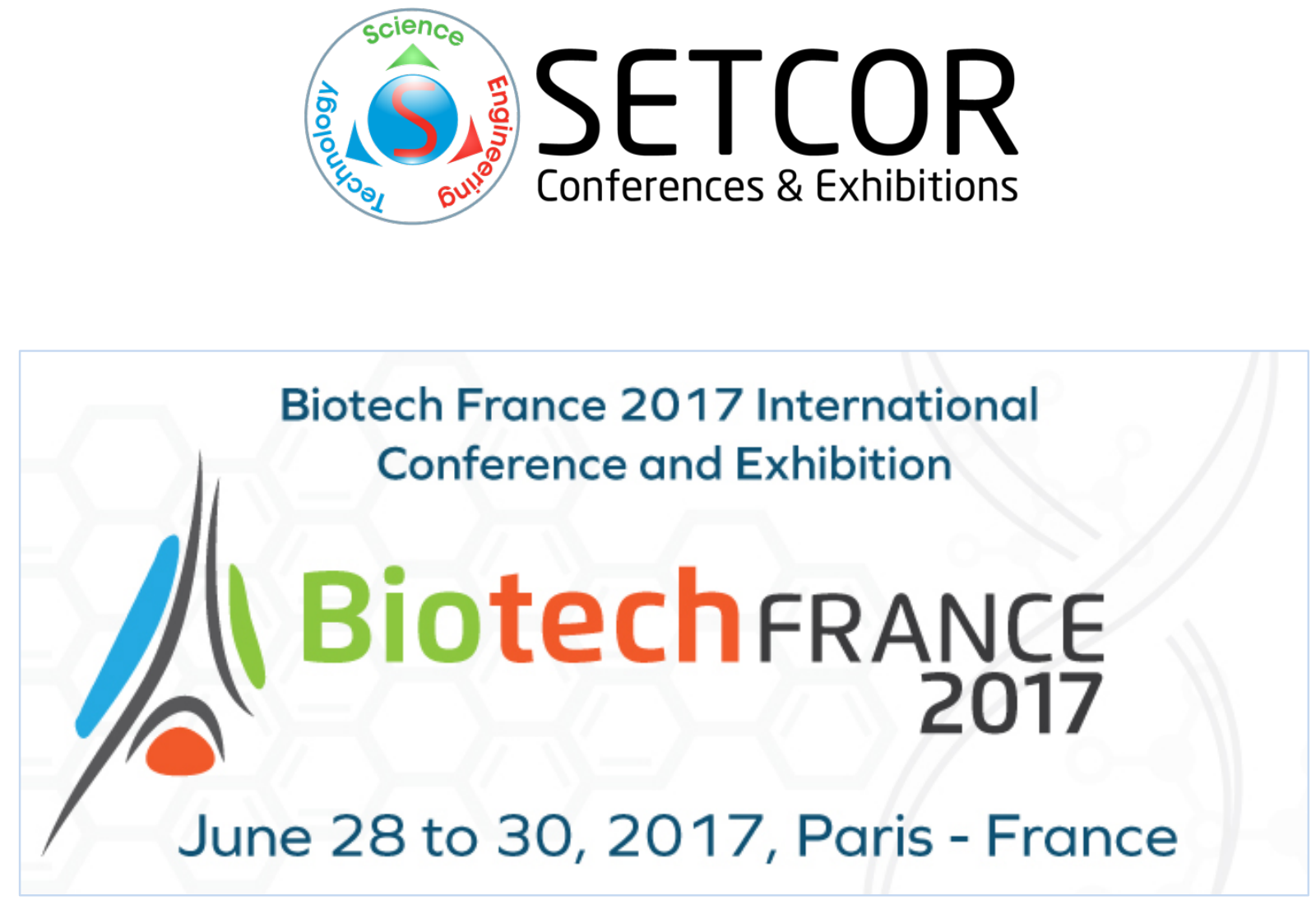

The International Conference for Biotechnology

Biotech France 2017

June 28 to 30, 2017, Paris - Korea

Conference Proceedings

DOI: https://doi.org/10.26799/cp-biotechfrance2017 


\title{
Sustainable bio-based materials: opportunities and challenges
}

\author{
Yvonne van der Meer ${ }^{1}$ \\ ${ }^{1}$ Maastricht University, Dept. of Biobased Materials, Aachen-Maastricht Institute for Biobased \\ Materials \\ Urmonderbaan 22,6167 RD Geleen, The Netherlands, Yvonne.vanderMeer@ maastrichtuniversity.nl
}

\begin{abstract}
Research in the area of bio-based materials aims to achieve breakthroughs in bio-based materials development. A novel way is presented to organise bio-based materials research with a value chain approach in which sustainability research is integrated in the research program. This research approach has been implemented in the Aachen-Maastricht Institute for Biobased Materials, a collaboration of Maastricht University and RWTH Aachen University. The institute is located on the Brightlands Chemelot Campus in Geleen, The Netherlands. Furthermore, a gap analysis was performed to evaluate the possibilities and challenges for sustainability assessments of bio-based materials. Sustainability assessments are needed to quantify and compare the level of sustainability of bio-based and fossil based materials solutions and to identify the sustainability challenges and opportunities of bio-based materials.
\end{abstract}

Keywords: bio-based materials, bio-based value chain, sustainability assessments, bio-based economy, circular economy

\section{Introduction}

Today's linear 'take, make, and dispose' economic model relies on large quantities of cheap, easily accessible resources and energy, and is reaching its ecological limits. In a circular economy, resources are regenerated in the biological cycle and recovered and restored in the technical cycle. This is an attractive and viable alternative economic model that businesses have already started exploring today [1]. Main drivers for change are societal challenges like climate change, resource scarcity, energy insecurity, waste problems and an increasing population with growing product demands.

Bio-based materials (i.e. materials made from renewable biological resources) hold great promise to become sustainable alternatives for fossil based materials due to renewable feedstock use, possibility to use (enzymatic) low energy production routes and possible alternative waste strategies, like biodegradation. Moreover, bio-based materials provide development opportunities for rural areas, including increased employment and increased added value generation for biomass producers and traders [2]. However, bio-based materials are not intrinsically sustainable. The biomass feedstock supply, manufacturing process, interdependency and competition with other product value chains, and waste scenarios play an important role in the level of sustainability. Moreover, sustainability issues like competition of biofuels production with food security have already been identified and should be taken care of when further developing the bio-based economy [2].

The transition to a bio-based economy is driven by the public and private demand for more sustainable products and by governmental bio-economy policies. Moreover, upcoming circular economy policies and the Paris climate conference (COP21) agreement further boost the development of a sustainable bio-based economy. However, the bio-based economy is still in an early stage of development. Technological and innovation challenges have to be tackled to develop sustainable and competitive bio-based products [2], thus to make the bio-based economy a reality. Main challenges are to develop viable new value chains and products based on renewable feedstocks, to develop innovative bio-based products for identified market applications and to create and accelerate the market uptake of bio-based products and applications [3]. 


\section{Approach}

Maastricht University, located in the Netherlands, RWTH Aachen University and Fraunhofer IME, both located in Germany, founded the Aachen-Maastricht Institute for Biobased Materials (AMIBM) in 2014. AMIBM investigates the whole value chain of bio-based materials from renewable resources to applied bio-based material products by joining technology platforms and research initiatives from the founding institutions. The focus is on new, higher value bio-based products with a lower market share. AMIBM closely works with industry and is located on the Brightlands Chemelot Campus, a community for open innovation in chemistry and sustainability, surrounded by industry of the Chemelot Industrial Park.

In 2016 AMIBM included sustainability of bio-based materials as a new research line in the institute. The head of the research line has performed a gap analysis to identify the research needs for sustainability assessments of bio-based materials and decision support tools for sustainability of biobased materials. The results are presented in section 3.2.

\section{Results and discussion}

\subsection{Bio-based materials research approach}

The founders of AMIBM bring in core competences in fundamental and applied research. The multidisciplinary and international team consists of established scientists with expertise in molecular biology \& ecology, organic chemistry, bio-catalysis, bio-based building blocks, polymer chemistry, polymer physics, textile engineering, tissue engineering, and sustainability evaluations. With this multidisciplinary team AMIBM is able to offer a unique approach covering the entire bio-based materials value chain from renewable resources via building blocks, polymers and materials to applied materials applications. In close collaboration with industrial partners, AMIBM hunts for novel materials based on renewable feedstock. AMIBM strives for innovation along the value chain by crossing borders of disciplines and also by making use of push \& pull dynamics within the institute: market pull from needs in (bio-based) materials applications, e.g. desired functionalities, and technology push from scientific discoveries that offer functionalities that can be translated into new or improved products, as depicted in figure 1.

The vision of the institute is to achieve a paradigm shift in the production, application and life cycle management of bio-based materials by making use of higher value resources, chemical upgrading of resources and intermediates, novel and more efficient materials fabrication technologies and by closing the loops from manufacturing to regeneration. These four strategies of AMIBM are outlined in figure 2. The success of this approach can only be evaluated when AMIBM has generated a vast amount of results. At this stage it can only be stated that AMIBM is developing beyond the expectations as projected in the AMIBM business case [4] and is gaining momentum to achieve its scientific ambitions. 


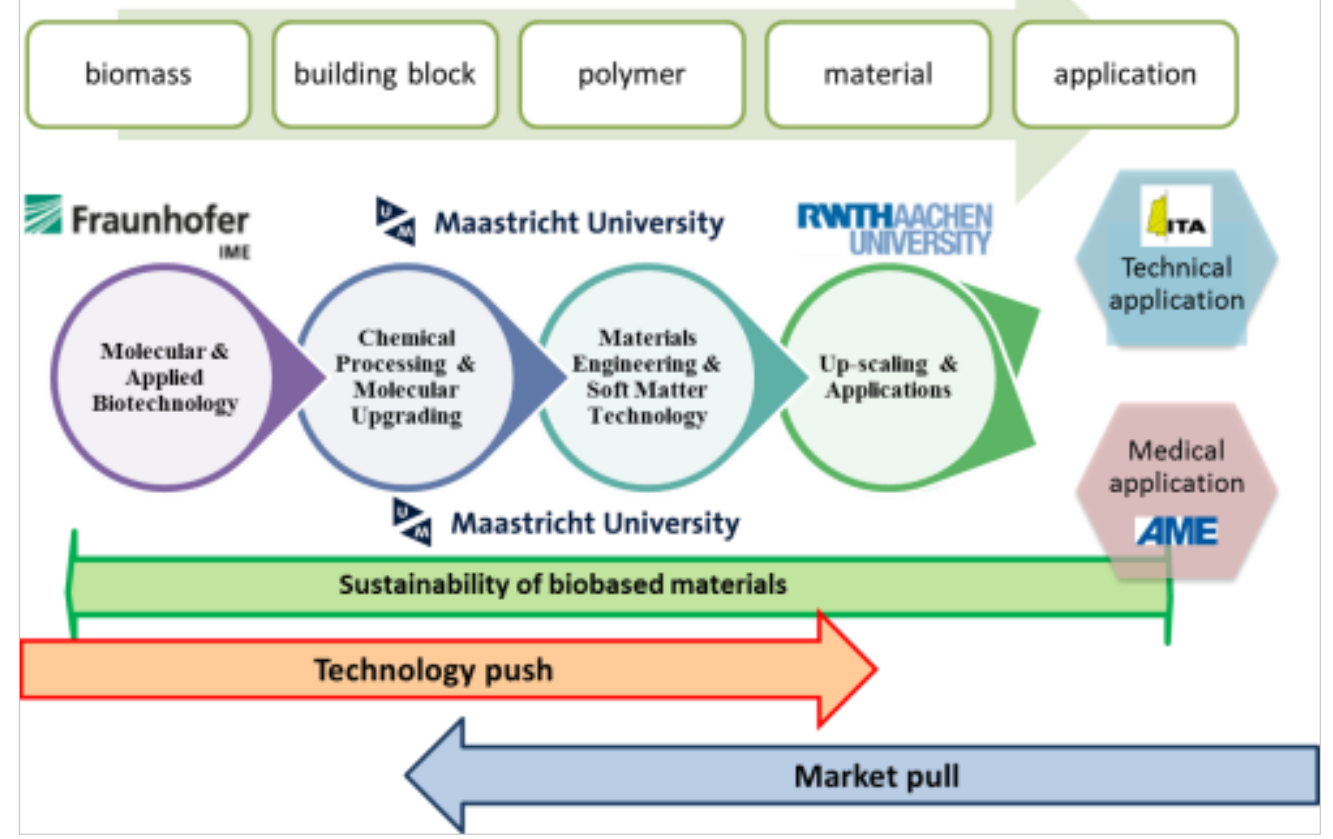

Fig. 1: Value chain approach of AMIBM: expertise from the founders of AMIBM jointly covers the value chain from biomass to applied materials. With this approach AMIBM also includes market pull and technology push dynamics with the aim to establish breakthroughs in bio-based materials development [4].

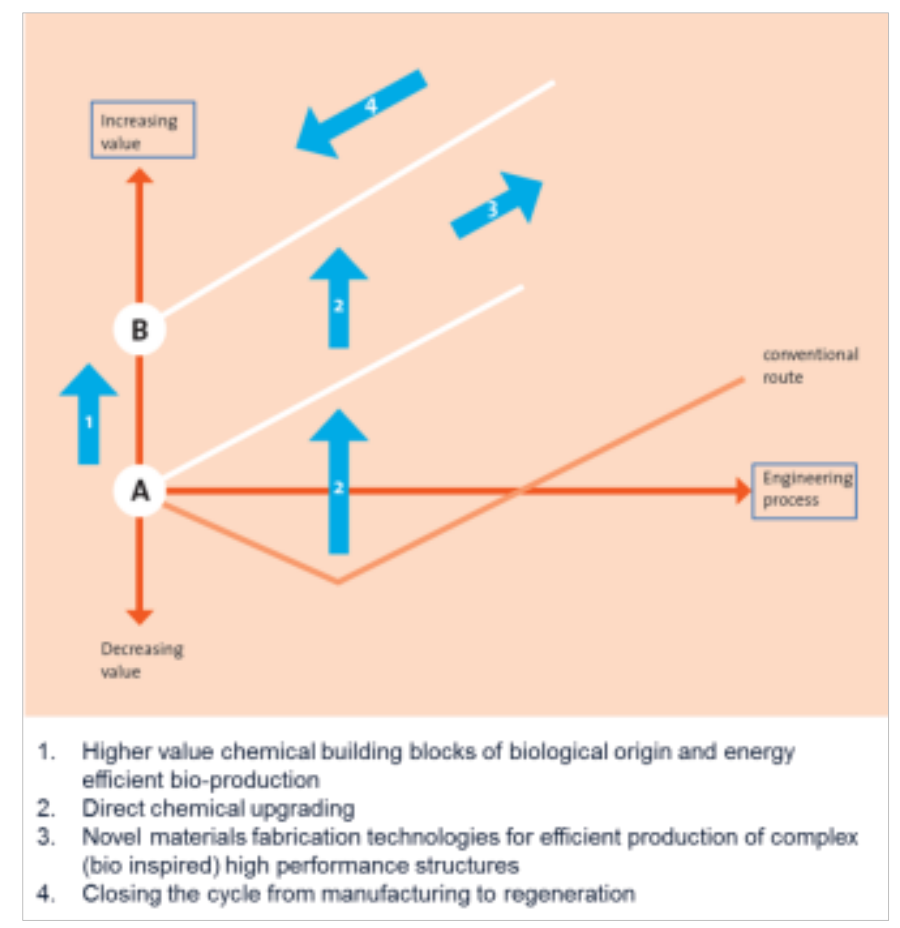

Fig. 2: Four strategies of AMIBM to achieve a paradigm shift in bio-based materials [4]

\subsection{Sustainability of bio-based materials}

With respect to sustainability, bio-based materials generally exert lower environmental impacts than conventional materials in the category of climate change, if greenhouse gas emissions from indirect land use change are not taken into account [5]. However, greenhouse gas emissions from land use 
change are relevant to consider in Life Cycle Assessments (LCAs) of bio-based materials [6]. Furthermore, bio-based materials may exert higher environmental impacts than their conventional counterparts in the categories of eutrophication and stratospheric ozone depletion [5]. Therefore, it is of vital importance to assess the environmental performance of (newly developed) bio-based materials and to investigate the expected environmental impact of bio-based materials under development. In addition, social and economic aspects are also important aspects of sustainability and therefore need to be investigated too.

Therefore, AMIBM initiated a sustainability assessment research line in 2016. This will enable AMIBM to assess the level of sustainability of bio-based materials solutions within the AMIBM research program and within research projects in collaboration with other partners. It will also support the selection of the most promising options in terms of sustainability for further development towards novel or improved bio-based materials applications. The gap analysis identified the most pressing issues that need further attention in sustainability research:

1. There are major shortcomings in current LCA studies hampering the proper evaluation of the environmental impact. LCA studies of bio-based materials need to address important aspects related to the renewable feedstock, like biogenic carbon, temporal effects of carbon sequestration, land-use change effects, soil degradation, regional differences of biomass production, and water use [5, 6].

2. Large differences are observed between LCA studies of bio-based materials, partly due to the diversity of methodological choices and assumptions made [5], so the methodology needs a higher degree of standardization and dedicated methods are needed to assess the environmental impact related to renewable feedstock production.

3. Most LCA studies on (bio-based) materials are cradle-to-gate studies [5], not taking into account the use of materials and end-of-life scenarios. Besides using renewable feedstock for materials production, applying circular economy principles, like closed-loop recycling, has great potential in economic and environmental terms. Inadequate waste management of materials, is causing environmental pollution and waste also represents economic value that is lost in a linear economy approach [1].

4. Economic sustainability indicators mainly exist for low value applications like biofuels [7] whereas bio-based materials are higher value applications. Therefore it is needed to further develop economic indicators tuned to bio-based materials.

5. Social impact of bio-based materials development is important, but barely researched. Available studies mostly limit to job creation, wages and work environment [8]. To evaluate social impact, guidelines for Social Life-Cycle Assessment of products were published by the UNEP/SETAC, providing a methodologic framework [9]. This framework can be a valuable tool for social impact assessments of bio-based materials.

6. Integration of environmental, economic and social assessments would make it possible to fully assess the sustainability of bio-based materials. It could also contribute to the development of decision support tools for sustainability of bio-based materials, e.g. to identify preferable tradeoffs between different sustainability aspects.

AMIBM will address the identified gaps in sustainability assessments in further research on sustainability of bio-based materials.

\section{Conclusion}

The Aachen-Maastricht Institute for Biobased Materials (AMIBM) has chosen a novel approach for bio-based materials research with a multidisciplinary research team covering the entire bio-based materials value chain from renewable resources via building blocks, polymers and materials to applied materials applications. AMIBM has integrated sustainability into the research portfolio. There are major scientific challenges to be tackled to be able to perform consistent and full sustainability assessments of bio-based materials, i.e. to evaluate the environmental, economic and social impact separately and in an integrated manner. 


\section{Acknowledgements}

This project has been made possible with the support of the Dutch Province of Limburg and the University Fund Limburg.

\section{References}

1. Ellen MacArthur Foundation, Towards the Circular Economy, Vol. 1: an economic and business rationale for an accelerated transition, Ellen MacArthur Foundation, 2013

2. J. W. A. Langeveld, , J. Dixon, and J. F. Jaworski, "Development Perspectives Of The Biobased Economy: A Review", Crop Sci. vol. 50, pp. S-142-S-151, 2010

3. Bio-based Industries Consortium (2017, May), "SIRA, Strategic Innovation and Research Agenda", [Online]. Available: http://biconsortium.eu/sites/biconsortium.eu/files/downloads/SIRA2017-Web.pdf

4. Y. van der Meer, D. Peschen, R. M Twyman, R. Fischer, S. De Wildeman, S. Rastogi, and S. Jockenhoevel, "Business case Aachen Maastricht Institute for Biobased Materials, Cross-border cooperation for a sustainable future", Maastricht University, 2014

5. M. Weiss, J. Haufe, M. Carus, M. Brandão, S. Bringezu, B. Hermann, M. K. Patel, "A review of the environmental impacts of biobased materials", J. Ind. Ecol., vol. 16, pp. S169-S181, 2012

6. P. Pawelzik, M. Carus, J. Hotchkiss, R. Narayan, S. Selke, M. Wellisch, M. Weiss, B. Wicke and M. K. Patel, "Critical aspects in the life cycle assessment (LCA) of bio-based materials Reviewing methodologies and deriving recommendations", Resources, Conservation and Recycling, vol. 73, pp. 211-228, 2013

7. M. Van Dael, N. Márquez, P. Reumerman, L. Pelkmans, T. Kuppens, and S. Van Passel, "Development and techno-economic evaluation of a biorefinery based on biomass (waste) streams - case study in the Netherlands", Biofuels, Bioprod. Bioref, vol. 8, pp. 635-644, 2014

8. A. Souza, M. D. B. Watanabe, O. Cavalett, "Social life cycle assessment of first and secondgeneration ethanol production technologies in Brazil" Int J Life Cycle Assess, 2016

9. C. Benoit and B. Mazijn (Eds) "Guidelines for social life cycle assessment of products". UNEP/SETAC Life Cycle Initiative, Paris, 2009 


\title{
Aerobic fermentation performance of Zymomonas mobilis mediated by microbubbles generated by fluidic oscillation
}

\author{
Ali R. Mulakhudair ${ }^{1,2}$, William Zimmerman ${ }^{1}$ \\ ${ }^{1}$ Department of Chemical and Biological Engineering, University of Sheffield, Mappin Street, Sheffield, UK, S1 \\ 3JD \\ Armulakhudair1@sheffield.ac.uk, W.zimmerman@sheffield.ac.uk \\ ${ }^{2}$ The University of Babylon, MOHEASR, Babil, Iraq
}

\begin{abstract}
Zymomonas mobilis has long been known as the best microbial producer of ethanol, and it is widely used to produce a large quantity of ethanol in anaerobic conditions, offering many advantages over other ethanol producers such as Saccharomyces cerevisiae. Under aerobic conditions, however, this bacterium produces a reasonable amount of acetaldehyde and carbon dioxide with lower quantity of ethanol. Acetaldehyde and carbon dioxide accumulation in the fermentation broth can cause severe inhibition for Zymomonas growth. Removing the accumulated acetaldehyde and carbon dioxide, however, reduces the chemical activity of the gaseous products with a negative value change in Gibbs free energy; hence the biological reactions become thermodynamically favourable and provides momentum for the formation of more products. Microbubbles generated by fluidic oscillation were used to remove both acetaldehyde and carbon dioxide from the fermentation broth. Using the microbubble technology periodically, however, preferentially produces the microbial biomass, acetaldehyde and carbon dioxide, while ethanol preferentially accumulates under anaerobic conditions with less biomass, acetaldehyde and carbon dioxide. Additionally, the oxygenation concurrent with the stripping process by microbubbles efficiently maintained the oxygen concentration in the fermentation broth above the critical oxygen concentration, leading to stable aerobic conditions.
\end{abstract}

Keywords: In situ product removal, aerobic fermentation, microbubble, Zymomonas.

\section{Introduction}

Zymomonas mobilis has long been used in equatorial regions to produce various sorts of alcoholic beverages. It uses the Entner-Doudoroff (ED) pathway to metabolise sugars (mainly glucose) to produce ethanol. This pathway produces one mole of ATP for each mole of glucose being metabolised [1]. Microorganisms have developed various glucose-consuming pathways as a part of the metabolism diversity, such as the Entner-Doudoroff (ED), EmbdenMeyerhof-Parnas (EMP) and phosphoketolase pathways. However, it has been argued that using any particular glucose metabolism pathway represents a bargain between the energy yield and the amount of proteins needed to catalyse the flux of the pathway [2].

There are many advantages of using Z. mobilis in the fermentation processes. These include: i) Large and specific uptake rates of glucose and ethanol production; ii) High ethanol productivity, which is close to theoretical productivity with relatively little amount of biomass formation; iii) Tolerance to high ethanol concentration, which may reach 16\% (v/v); and iv) Feasibility for genetic manipulation [3]. While the wild strain of Z. mobilis can use only a narrow range of sugars (such as glucose, fructose, and sucrose) as a sole carbon source, recombinant strains have been developed to utilise pentose sugars such as xylose and arabinose as well as hexoses sugars[4].

Interestingly, Z.mobilis has a respiratory electron transport chain, and it shows an increased growth yield during the exponential phase of the aerobic growth. Concurrently, ethanol productivity decreases and other products start to be accumulated, which are reduced metabolites such as acetaldehyde and acetate [1]. This chain competes with the alcohol dehydrogenase reaction, as both reactions use reducing equivalents NAD (P) H as a cofactor[5].

The aim of the study is to test the performance of Zymomonas mobilis in the microbubble-dosed aerobic fermentation system and to produce acetaldehyde as a target product. 


\section{Materials and Methods}

\subsection{Bacterial preparation}

Zymomonas mobilis ZM4 (ATCC® 31821) was first activated using RM medium which was suggested by the provider (ATCC in partnership with LGC Standards), in a 1L Erlenmeyer flask with continuous shaking at $100 \mathrm{rpm}$. Thereafter, the bacterium was cultivated using the fermentation medium [6].

\subsection{Experimental procedures}

Zymomonas mobilis was cultivated on the fermentation medium after pre-cultivating it on the RM medium. This bacterium was incubated at $30^{\circ} \mathrm{C}$ and $\mathrm{pH} 5.5$ for several days $(30-50 \mathrm{~h})$, and acetaldehyde and ethanol concentrations were measured using a gas chromatography. Firstly, the fermentation process was achieved under standard conditions without sparging microbubble (Preliminary studies). This step was done to study different aspects of bacterial growth and bioproducts production under standard conditions with the initially sparging microbubble and with using the wild-type strain (Zymomonas mobilis ZM4). Secondly, the fermentation process was conducted using the periodical sparging with air microbubbles. Both durations of sparging and flow rate were chosen according to the experimental data (However, the flow rate was stabilized at $0.3 \mathrm{~L} / \mathrm{min}$ ). This process was achieved using an airlift loop bioreactor (Figure 1). Samples were taken every 1 hour for the trial experiments to evaluate the system and to better understanding of the whole process, and then the sampling time was determined to be two hours. These samples were analyzed using a gas chromatography (Shimadzu, UK), to quantify the products (Acetaldehyde and Ethanol) [6] and also glucose concentration using the protocol described by Miller, [7]. However, the biomass concentration was measured on an hourly basis.

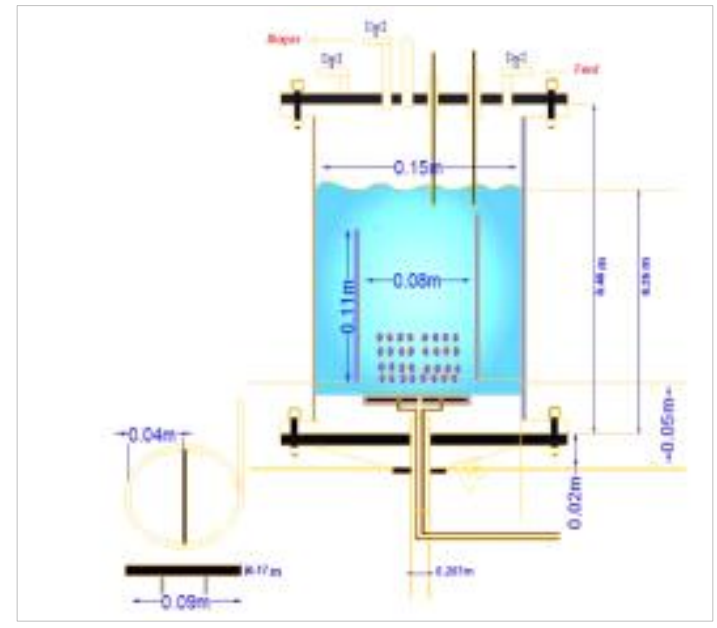

Figure 1: Experiment set up. Air from the fluidic oscillator passes through the fluidic oscillator to feed the microbubbles diffuser. there are two outputs from the fluidic oscillator with two bleeding on both sides to control the oscillatory flow.

Two identical bench-scale fermenters were used in the current study. Each fermenter has an overall volume of 15 liters with working volume of 9 liters (Figue 1). The time of each experimental set was determined according to the glucose consumption, biomass concentration and the results gained from the preliminary studies. These fermenters were operating under mesophilic conditions $\left(\sim 30^{\circ} \mathrm{C}\right)$.

A PID controller was used to control the temperature in the reactor at $30^{\circ} \mathrm{C}$. The reactor was also provided with a $\mathrm{pH}$ controller, type ON/OFF controller (Model BL931700 pH mini controller) to control the $\mathrm{pH}$ in the fermenter. The solution used to adjust the $\mathrm{pH}$ during the fermentation process, is $1 \mathrm{M}$ sodium bicarbonate, and this solution has several advantages over other bases such as sodium hydroxide. For example, this solution is less corrosive and toxic than $\mathrm{NaOH}$, it does not cause any precipitation in the fermenter, and more importantly, this solution adjusts the $\mathrm{pH}$ gradually, and it does not cause change the $\mathrm{pH}$ value significantly with excessive doses. No acidic solutions were used to adjust the $\mathrm{pH}$ in the current study as the $\mathrm{pH}$ tends to decrease in the fermentation process due to carbon dioxide and acids production during the fermentation process and thus, only alkaline solutions were needed to adjust $\mathrm{pH}$. 
Produced biogas (carbon dioxide) was measured every day, and this measurement was achieved by displacement of the aqueous acid solution $(\mathrm{pH} \leq 3)$. The carbon dioxide concentration was measured using carbon dioxide monitor (Data gas analyzer, Model 0518) at 1 atm pressure.

\section{Results and Discussion}

\subsection{Oxygen requirement of the fermentation system}

Oxygen plays a very important role in the fermentation process of Zymomonas mobilis ZM4. Depending on whether the process is aerobic or anaerobic, the fermentation products can be changed. Zymomonas mobilis tends to accumulate less reduced metabolite, acetaldehyde and ethanol under aerobic conditions, while ethanol preferentially accumulates under anaerobic conditions. Sparging air-microbubbles in the fermentation system can achieve two main purposes. The first is to provide enough oxygen for the Zymomonas growth and propagation. The second is to strip out some fermentation products such as acetaldehyde, carbon dioxide and, a lesser extent, ethanol.

Oxygen uptake rate is constant during the fermentation process as long as the oxygen concentration is above the critical biological concentration, where the microbial cells have not yet been starved for oxygen[8]. The exact value of the critical oxygen concentration depends on the microorganism, and this value usually falls between 5\% and 10 $\%$ of the air saturation under average operational conditions [9]. Taking these values into account as well as considering studies from Ishikawa et al., [10] and Bringer et al., [11], $0.83 \mathrm{ppm}$ was used as the critical oxygen concentration in these experimental sets, which equals more than $10 \%$ of oxygen saturation in the fermentation medium. This oxygen concentration can be seen as a safe choice to keep the whole fermentation process aerobic.

To save energy and to keep the operational cost low with effcient products stripping, air-microbubbles were sparged periodicially. Air-microbubbles were introduced to the fermentation system until oxygen concentration equilibrium was achieved. Thereafter, the sparging was stopped, and the system was left to consume the provided oxygen. When the oxygen concentration dropped to about the critical oxygen concentration, the air supply was turned on again. Two periods were identified during the aeration. The first period was at the beginning of the fermentation process, when the oxygen concentration reached its saturation concentration at $30^{\circ} \mathrm{C}$ to $\sim 8.28 \mathrm{ppm}$. In the second period, the system had already started to produce the fermentation products such as carbon dioxide (gas) and acetaldehyde (which tended to be vapor at $30^{\circ} \mathrm{C}$ ), and this changed the equilibrium of oxygen in the system. The new equilibrium concentration was reached $\sim 4.7 \mathrm{ppm}$ (Figure 2). 


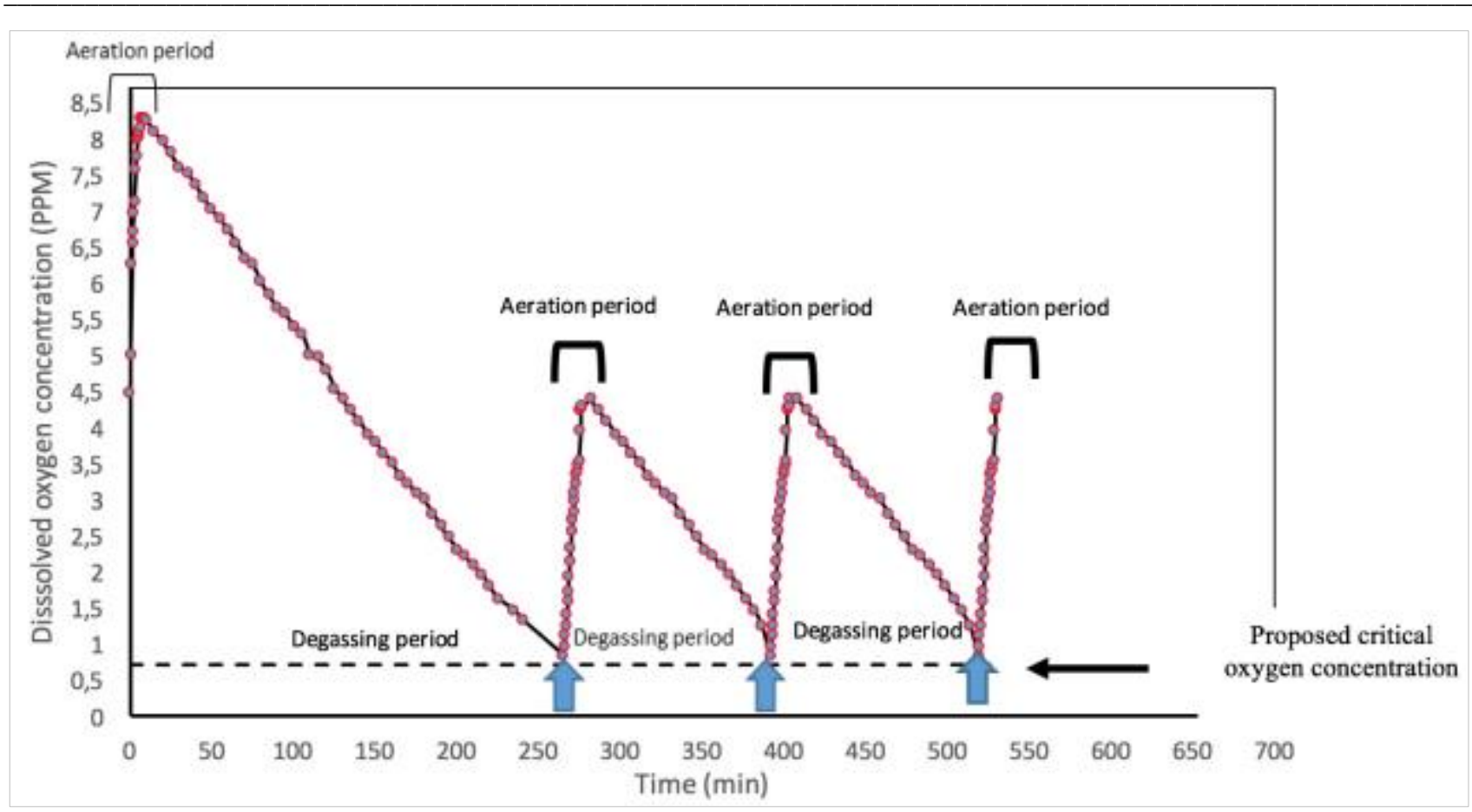

Figure 2: A model of periodical oxygen dosing and consuming in Zymomonas fermentation culture. The readings are representative of triplicate results.

The rational interpretation for these two periods is that the oxygen mass transfer response follows the thin film theory, in which the mass transfer response is inherently transient in small microbubbles [12], [13]. In the first period, the oxygen mass transfer is sufficiently fast. Therefore, the internal concentration of oxygen in the microbubbles is significantly reduced as there is a significant driving force for oxygen transfer from the microbubble to the fermentation medium and eventually to the microbial cells. This nonequilibrium driving force is decreased as microbubbles rise in the fermentation broth. Ultimately, if the bubble composition of gases reaches equilibrium with the bulk liquid concentration, this driving force for the mass transfer vanishes[14]. Concurrently, the bacterial culture would be in the lag phase, and will have just started to consume the oxygen.

At the second period of the aeration, when the fermentation process has already begun, the bacterial culture starts consuming oxygen, and many gaseous products are produced. The equilibrium of the system changes and the bubble composition varies. During this period, the produced gases accumulate in the bulk liquid, and they tend to diffuse into microbubbles, and this might lead to reducing the equilibrium concentration, reducing the nonequilibrium driving force. Figure 2 shows the oxygen consumption pattern in the Zymomonas fermentation culture with a twostaged aeration pathway.

\subsection{Glucose consumption pathway}

Generally, Zymomonas mobilis catabolises around $95-98 \%$ of the carbon source (glucose) into ethanol and carbon dioxide, while just 3-5\% of this carbon source can be used in biomass formation and to serve an anabolic role [15], [16]. Figure 3 shows the glucose consumption pattern and glucose consumption rate in both control and periodically sparging groups. 
(A)

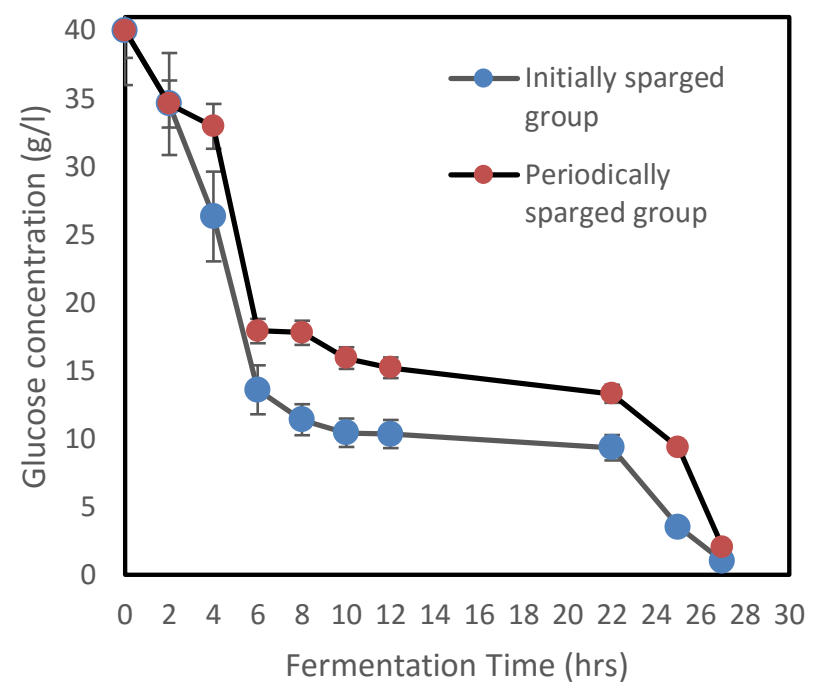

(B)

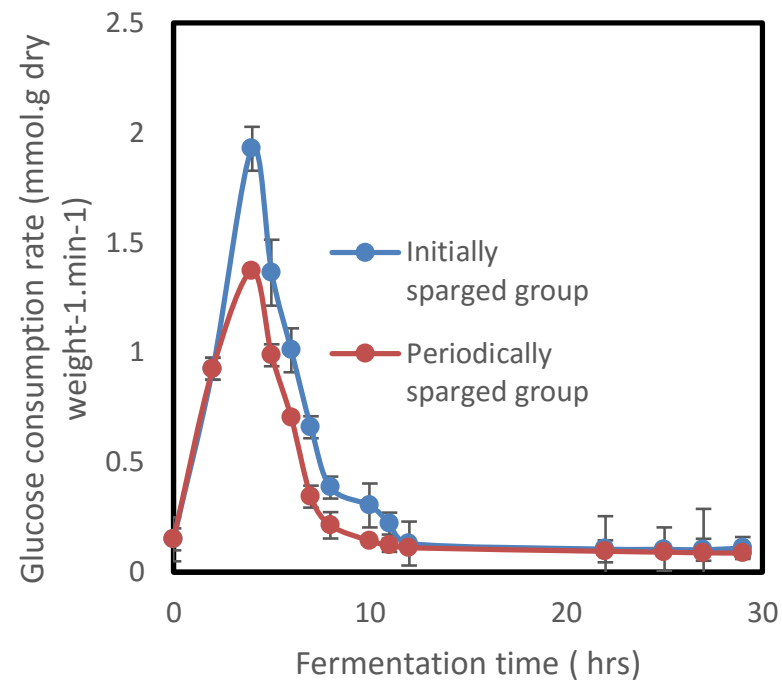

Figure 3: Glucose consumption pattern in Zymomonas mobilis. (A) Glucose concentration against time. (B) Glucose consumption rate in both initially and periodically sparged groups. Error bars depict standard deviation.

Carbohydrate metabolism in Zymomonas mobilis can be seen as a true catabolic highway [17]. Anaerobically, $Z$. mobilis cells convert glucose into ethanol and carbon dioxide at 3 to 5 times faster than the glucose consumption rate in yeast [15]. The high glucose consumption rate was one of the reasons to use this bacterium in the current study. Moreover, the glucose consumption rate in this bacterium is also 1.2 to 1.5 times faster than Streptococcus bovis, which is another promising obligatory fermentative microorganism[18].

Initially, both groups were started at the same level of oxygen, and both groups showed almost the same pattern of biomass production (Figure 4) and glucose consumption (Figure 3) at the first 3 hours of the fermentation process. Thereafter, the initial sparging group was kept without any oxygen supply, while the periodically-sparged group was regularly aerated. 4 hours were required to reach the critical level of oxygen in both groups, and further oxygen starvation led to a shift in the metabolism pathway into the anaerobic fermentation. Ishikawa et al., [9] previously, reported the same observation. Two scenarios were expected depending on the dissolved oxygen level: the first happenes under high concentration of the dissolved oxygen (higher than the critical oxygen level), and the second occurres at relatively low dissolved oxygen concentration (lower than the critical oxygen concentration). NADH oxidase is the enzyme, which is responsible for the oxidation of NADH with oxygen, and thus, the oxygen consumption happens because of the activity of this enzyme [10]. Under the first scenario, the activity of NADH oxidase is directly adapted with the dissolved oxygen concentration, and its activity increases as the concentration of the dissolved oxygen increases [10]. When the concentration of the dissolved oxygen is above the critical oxygen level, the NADH becomes limited because of the NADH oxidation by NADH oxidase, and therefore, less NADH (which is formed by an Entner-Doudoroff pathway) is available to reduce the acetaldehyde into ethanol by the alcohol dehydrogenase enzyme. In the second scenario, the concentration of the dissolved oxygen is nearly zero (lower than the critical oxygen level) when most of the formed NADH becomes available for the reduction of acetaldehyde into ethanol by alcohol dehydrogenase [9]. 


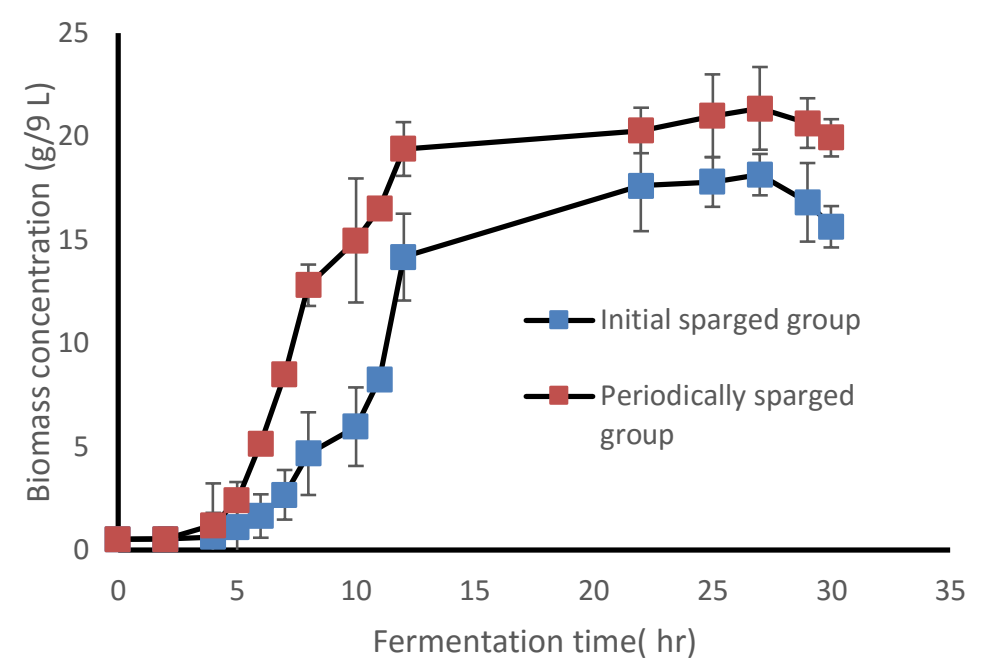

Figure 4: Comparison between the growth pattern of Zymomonas mobilis within control and periodical sparging strategies. Error bars depict standard deviation.

\subsection{Fermentation products (Acetaldehyde, ethanol, and carbon dioxide)}

Figure 5 (A, B) shows both acetaldehyde and ethanol production profiles during the fermentation process. In Figure 5(A), the ethanol production was almost the same between the two groups during the first 10 hours, and therafter, the diversion between the two groups started and continued until the end of the fermentation process. Interestingly, this deviation was expected to happen after almost 4 hours at the point at which the dissolved oxygen concentration was depleted and the metabolism was thought to shift to an anaerobic pathway gradually after this duration. There was around 39\% more ethanol produced in the initially-sparged group in comparison with the periodically-sparged group. This result agrees with the proposed scenarios, which suggested that there is less NADH available to the alcohol dehydrogenase to convert acetaldehyde to ethanol under aerobic conditions.

On the other hand, in Figure 5(B), acetaldehyde started to accumulate in the fermentation broth after just 2 hours from the beginning of the fermentation, and continued to accumulate within the broth and reached its highest point after 10 hours. Therafter, the production decreased until the end of the fermentation process. It can be seen from Figure 5(B) that the periodically-sparged group produced around 108\% more acetaldehyde than the initially- sparged group and the acetaldehyde is contineousely being stripped out from the periodically sparged group with $99 \%$ efficiency. The accumulation of acetaldehyde in the periodically-sparged group during the first 10 hours might explain the increased concentration of ethanol, which was seen in this period. The concentration of substrate (acetaldehyde) is a key factor affecting the rate of reaction catalysed by an enzyme. Thus, increasing the acetaldehyde concentration in the periodically-sparged group increased the ethanol production by alcohol dehydrogenase, a linear increase with a concentration of acetaldehyde when it is at relatively low concentrations. With the further accumulation of acetaldehyde, the reaction velocity of alcohol dehydrogenase could increase by smaller and smaller amounts in response to an increase in the substrate (acetaldehyde) concentration. Finally, the enzymatic reaction reaches its michaelis-menten threshold, where the reaction velocity becomes very small as the acetaldehyde concentration increases[19]. Figure 6 shows the total carbon dioxide produced at the end of the fermentation process ( 27 hours ) collected by the gas collection system. Regarding the carbon dioxide, the initially sparged group produces $0.15 \mathrm{Mm}$, while the periodically sparged group produces around $1 \mathrm{Mm}$, more than 5-fold increase. 
(A)

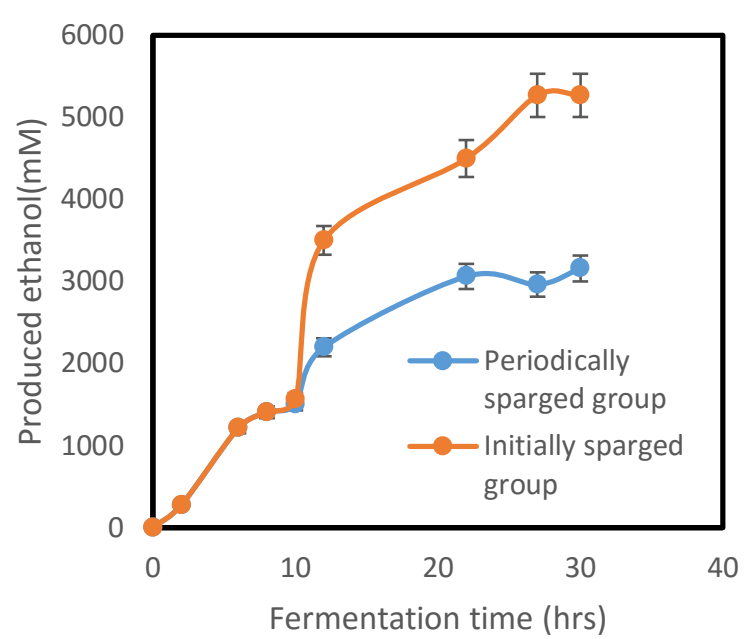

(B)

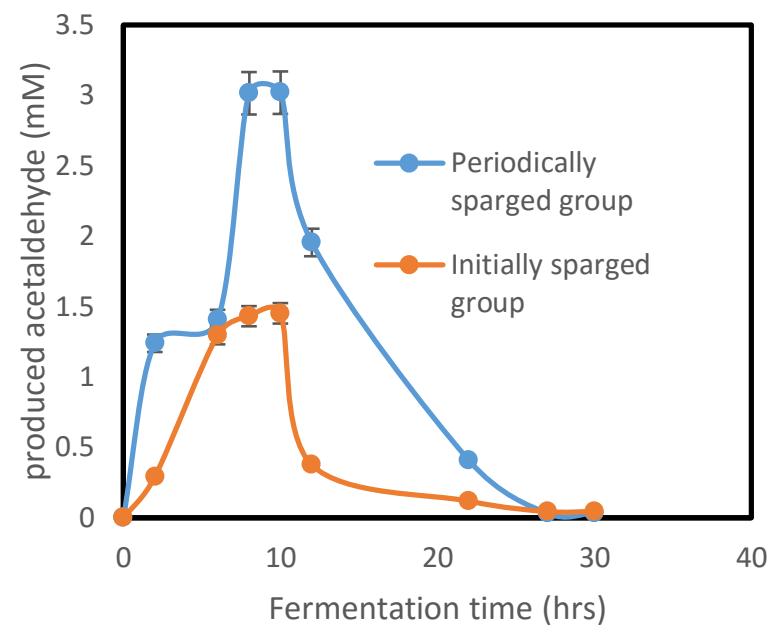

Figure 5: Acetaldehyde and Ethanol production during the fermentation process. (A) Ethanol production (B) Acetaldehyde production. Error bars depict standard error.

\section{Conclusion}

The study aims to test the performance of Zymomonas mobilis under aerobic conditions using glucose as a carbon source. The results show that using microbubble technology can remove acetaldehyde from the fermentation broth with $99 \%$ efficiency, leading to relatively high microbial growth. Using the microbubble technology, however, gives $45 \%$ yield of ethanol and $1 \%$ yield of acetaldehyde with $110 \%$ yield of microbial biomass in comparison with $70 \%$, $0.5 \%$ and $90 \%$ yield for ethanol, acetaldehyde and biomass, respectively, in the initially-sparged group. The periodically-sparged group produces 566\% more carbon dioxide than the initially-sparged group. The oxygenation concurrent with the stripping process by the periodical sparging strategy efficiently maintained the oxygen concentration in the fermentation broth above the critical oxygen concentration, leading to stable aerobic conditions. The developed approach has potentially significant ramifications, particularly for fermentation-based industries, and it promises to offset many traditional aerobic fermentation deficiencies.

\section{Acknowledgements}

ARM would like to thank the Iraqi Ministry of Higher Education and Scientific Research for the doctoral Scholarship. WZ and ARM would like to acknowledge support from the ERA-IB/Z-fuels project. WZ thanks the EPSRC for grant no. EP/N011511/1.

\section{References}

1. J.-S. Seo et al., "The genome sequence of the ethanologenic bacterium Zymomonas mobilis ZM4.," Nat. Biotechnol., vol. 23, no. 1, pp. 63-8, Jan. 2005.

2. A. Flamholz, E. Noor, A. Bar-Even, W. Liebermeister, and R. Milo, "Glycolytic strategy as a tradeoff between energy yield and protein cost.," Proc. Natl. Acad. Sci. U. S. A., vol. 110, no. 24, pp. 10039-44, Jun. 2013.

3. P. Rogers, K. Lee, and D. Tribe, "Kinetics of alcohol production by Zymomonas mobilis at high sugar concentrations," Biotechnol. Lett., 1979.

4. K. Deanda, M. Zhang, C. Eddy, and S. Picataggio, "Development of an arabinose-fermenting Zymomonas mobilis strain by metabolic pathway engineering.," Appl. Environ. Microbiol., vol. 62, no. 12, pp. 4465-70, Dec. 1996.

5. U. Kalnenieks, N. Galinina, M. M. Toma, and R. K. Poole, "Cyanide inhibits respiration yet stimulates aerobic growth of Zymomonas mobilis.," Microbiology, vol. 146 ( Pt 6, pp. 1259-66, Jun. 2000.

6. R. R. Z. and M. Wecker, "Microbiological production of acetaldehyde," 4,900,670, 1990. 
7. G. L. Miller, "Use of Dinitrosalicylic Acid Reagent for Determination of Reducing Sugar," Anal. Chem., vol. 31, no. 3, pp. 426-428, 1959.

8. R. B. and A. E. HUMPHREY, "Dynamic measurement of the volumetric oxygen transfer coefficient in fermentation systems.," Biotechnol. Bioeng., vol. 104, no. 5, pp. 841-853, 1967.

9. Pauline M Doran, Bioprocess engineering principles, 2nd ed. Waltham, MA : Academic Press, 2013.

10. H. Ishikawa, H. Nobayashi, and H. Tanaka, "Mechanism of fermentation performance of Zymomonas mobilis under oxygen supply in batch culture," J. Ferment. ..., vol. 70, no. I, pp. 3440, 1990.

11. S. Bringer, R. Finn, and H. Sahm, "Effect of oxygen on the metabolism of Zymomonas mobilis," Arch. Microbiol., pp. 376-381, 1984.

12. M. D. Bredwell and R. M. Worden, "Mass-transfer properties of microbubbles. 1. Experimental studies.," Biotechnol. Prog., vol. 14, no. 1, pp. 31-8, 1998.

13. R. Mark Worden and Marshall D. Bredwell, "Mass-Transfer Properties of Microbubbles. 2. Analysis Using a Dynamic Model," vol. 14, no. 1, pp. 39-46, 1998.

14. M. K. H. Al-Mashhadani, H. C. H. Bandulasena, and W. B. Zimmerman, "CO 2 mass transfer induced through an airlift loop by a microbubble cloud generated by fluidic oscillation," Ind. Eng. Chem. Res., vol. 51, no. 4, pp. 1864-1877, 2011.

15. J. Swings and J. De Ley, "The biology of Zymomonas.," Bacteriol. Rev., vol. 41, no. 1, pp. 1-46, 1977.

16. P. L. Rogers, K. J. Lee, M. L. Skotnicki, and D. E. Tribe, "Ethanol production by Zymomonas mobilis," Vacuum, no. 1, 1982.

17. G. A. Sprenger, "Carbohydrate metabolism in Zymomonas mobilis: A catabolic highway with some scenic routes," FEMS Microbiology Letters, vol. 145. pp. 301-307, 1996.

18. G. M. Cook and J. B. Russell, "Energy-spilling reactions of Streptococcus bovis and resistance of its membrane to proton conductance.," Appl. Environ. Microbiol., vol. 60, no. 6, pp. 1942-8, 1994.

19. D. L. N. A. L. L. M. M, Lehninger principles of biochemistry, 5th ed. New York : W.H. Freeman, 2008. 


\title{
Antioxidant and cytotoxic properties of non-conventional food plant, Parkia timoriana (DC.) Merr.
}

\author{
G. J. Sharma \\ Department of Life Sciences, Manipur University, Imphal 795003, India
}

\section{Introduction}

The tree bean, Parkia timoriana (DC.) Merr. is widely distributed in the north-east India and south-east Asia, and is largely consumed for its rich protein content and characteristic flavor which is due to the presence of thioproline (Figure 1). Thioproline (thiazolidine-4-carboxylic acid) is a cyclic sulfur-containing amino acid, and its endogenous formation is considered as a detoxification pathway of formaldehyde. Some anti-tumor effects of thioproline in cancer patients have been clinically reported (Brugarolas and Gosalvez, 1980; Tahira et al. 1996). Thioproline is an effective nitrite-trapping agent in human body thereby inhibiting endogenous formation of carcinogenic N-nitroso compounds (Tsuda and Kurashima, 1997). Supplementation of diet with thioproline has been shown to stimulate lymphocyte functions and increased immune activities in old rats (Correa et al. 1999). So far, experiments conducted by various workers have used synthetic compound but studies involving natural thioproline from plant-based food has not been investigated. In this paper, investigations have been made with regard to antioxidant properties of thioproline using DPPH radical assay, hydroxyl radical scavenging and inhibition of superoxide radicals.

Cytotoxic properties using MTT [3-(4,5-di-methylthiazol-2-yl)-2,5-diphenyltetrazolium bromide] assay in mouse embryo fibroblast cell line $\mathrm{NIH} / 3 \mathrm{~T} 3$ which is used as tumor model has been made. The cell line grows as layers of flat, spread out cells whereas transformed fibroblasts are rounded up and grown in cell masses. Eventually, NIH/3T3 cells are not normal fibroblasts and these cells have been adapted to grow in culture over years and passed through some of the changes characteristic of tumor cells (Todaro and Green, 1963). Therefore, while cytotoxicity testing is performed, these cells are often used as model tumor cells.

\section{Materials and Methods}

\section{Seed material and extraction}

Fully matured seeds were removed from the seed pod, and the outer seed covers were removed with a sharp scalpel. One gram dry weight equivalent was ground using mortar and pestle, and the paste was homogenized with $10 \mathrm{ml} \mathrm{60 \%} \mathrm{methanol.} \mathrm{The} \mathrm{homogenate} \mathrm{was} \mathrm{centrifuged} \mathrm{at} 6000 \mathrm{~g}$ for $10 \mathrm{~min}$ to get clear supernatant. Finally, the supernatant was filtered through Whatman No. 1 filter paper and stored at $4^{\circ} \mathrm{C}$.
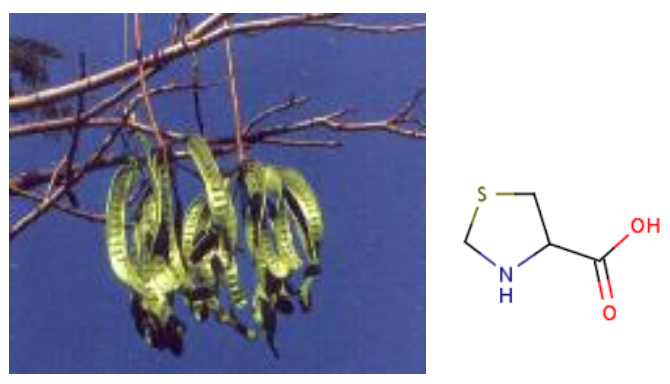

Figure 1: Seed pod of tree bean, Parkia timoriana (left) and chemical structure of thioproline (right)

\section{Chemicals and reagents}

Chemicals and reagents were purchased from Sigma Aldrich Co., USA and Merck, Germany. 


\section{DPPH radical assay}

The chemical assay was carried out using pure thioproline as described by Cuendet et al. (1997) with slight modification. The reaction mixture consisted of $250 \mu \mathrm{M}$ DPPH in $100 \%$ methanol with $0.1-5 \mathrm{mM}$ thioproline. After 30 min incubation period in the dark at room temperature, the absorbance was read against a blank at $517 \mathrm{~nm}$. Percentage inhibition was determined by comparison with methanol treated control group. The percentage of DPPH decoloration was calculated as follows:

$\%$ DPPH decoloration $=[1-$ O.D. sample/ O.D. control $] \times 100$

The degree of decoloration indicates the free radical scavenging efficiency of the compound. Values are presented as mean \pm standard deviation of three determinations.

\section{Hydroxyl radical scavenging assay}

Hydroxyl radical $(\mathrm{OH})$ scavenging activity assay was carried out by measuring the competition between deoxyribose and thioproline for hydroxyl radicals generated from $\mathrm{Fe}(\mathrm{II}) /$ ascorbate/ EDTA/ $\mathrm{H}_{2} \mathrm{O}_{2}$ system. The attack of hydroxyl radical to deoxyribose leads to thiobarbituric acid reactive substance (TBARS) formation (Kunchandy and Rao, 1990). Various concentrations of Parkia timoriana seed extract (2-400 $\mu \mathrm{g} / \mathrm{ml}$ ) were added to the reaction mixture containing $2.8 \mathrm{mM}$ deoxyribose, $25 \mu \mathrm{M} \mathrm{FeCl}_{3}, 100 \mu \mathrm{M}$ EDTA, $100 \mu \mathrm{M}$ ascorbic acid, $2.8 \mathrm{mM} \mathrm{H}_{2} \mathrm{O}_{2}$ and $5 \mathrm{mM}$ phosphate buffer (pH 7.4), making up a final volume of 1.0 $\mathrm{mL}$. The reaction mixture was incubated at $37^{\circ} \mathrm{C}$ for $1 \mathrm{hr}$. The TBARS formed were measured by using the method of Okhawa et al. (1979). One milliliter of thiobarbituric acid (TBA, $1 \% \mathrm{w} / \mathrm{v}$ in $50 \mathrm{mM} \mathrm{NaOH}$ ) and 1 $\mathrm{mL}$ of trichloroacaetic acid, $2.8 \% \mathrm{w} / \mathrm{v}$ ) were added to test tubes and incubated at $100^{\circ} \mathrm{C}$ for $30 \mathrm{~min}$. After the mixtures cooled, absorbance was measured at $532 \mathrm{~nm}$ against a blank containing deoxyribose and buffer. Reactions were carried out in triplicate. Inhibition (I) of deoxyribose degradation in percentage was calculated in the following way:

$\mathrm{I}=\left(\mathrm{A}_{\mathrm{o}}-\mathrm{A}_{1}\right) / \mathrm{A}_{\mathrm{o}} \times 100$

where $A_{o}$ is the absorbance of the control reaction (containing all reagents except the test compound) and $A_{1}$ is the absorbance of the test compound.

\section{Inhibition of superoxide radical}

Superoxide radical generated by hypoxanthine/ xanthine oxidase system was determined spectrophotometrically using the method of Lee et al. (2006) by monitoring the product of nitroblue tetrazolium (NBT). Various concentrations of Parkia timoriana seed extract $(10-50 \mu \mathrm{g} / \mathrm{ml})$ were added to the reaction mixture containing $100 \mathrm{ml}$ of $30 \mathrm{mM}$ EDTA (pH 7.4), $10 \mathrm{ml}$ of $30 \mathrm{mM}$ hypoxanthine in $50 \mathrm{mM}$ $\mathrm{NaOH}, 200 \mathrm{ml}$ of $1.42 \mathrm{mM}$ NBT and the final volume of $3 \mathrm{ml}$ was made up by $50 \mathrm{mM}$ phosphate buffer (pH 7.4). After adding $100 \mathrm{ml}$ of $0.5 \mathrm{U} / \mathrm{ml}$ xanthine oxidase, the reaction mixture was incubated for $30 \mathrm{~min}$ at $25^{\circ} \mathrm{C}$. The absorbance was read at $560 \mathrm{~nm}$ and compared with control samples in which the enzyme xanthine oxidase was not included. Inhibition of superoxide radicals was calculated from the optical density of treated and control samples:

Inhibitory effect $(\%)=\left[\left(\mathrm{A}_{560}\right.\right.$ control $-\mathrm{A}_{560 \text { sample }} / \mathrm{A} 560$ control $] \times 100$

\section{Cytotoxicity tests}

In vitro cytotoxic effect of crude extract of Parkia timoriana seed was investigated using mouse embryo fibroblast cell line (NIH/3T3). The 60\% methanol extract was dissolved in dimethylsulphoxide (DMSO). The mouse embryo fibroblast cell line NIH/3T3 was procured from National Centre for Cell Science, Pune, India. 


\section{Cell culture conditions}

Stock cells were cultured in Duelbecco's modified Eagle medium (DMEM) with $10 \%$ fetal calf serum supplemented with $0.04 \mathrm{M} \mathrm{NaHCO}_{3}, 0.006 \%$ penicillin and $0.025 \%$ streptomycin at $37^{\circ} \mathrm{C}$ in an atmosphere of $5 \% \mathrm{CO}_{2}$ and $95 \%$ humidity. The medium was changed every three days. Monolayer cells were plated out at $2 \times 10^{4}$ cells per well in 96-well microtitre plate. The cell growth was found to be exponential during 2-3 days in the medium.

\section{MTT assay}

MTT [3-(4,5-dimethylthiazol-2-yl)-2,5-diphenyltetrazolium bromide] easily enters cells. The esterases present in viable cells can cleave MTT to form purple-colored formazan crystals which are then solubilized. Color produced is directly proportional to cell viability. The cytotoxic effect of the crude extract, expressed as cell viability, was assessed by MTT staining experiment (Mosmann, 1983). In brief, confluent cultures of $\mathrm{NIH} / 3 \mathrm{~T} 3$ cells were treated with medium containing the $60 \%$ methanol extract of Parkia timoriana seeds at concentrations from 2-400 $\mu \mathrm{g} / \mathrm{mL}$. The extract was first dissolved in absolute DMSO and then in DMEM. The final concentration of DMSO in the test medium and controls was $<1 \%$. Cells were exposed for $48 \mathrm{hr}$ to test medium with or without the extracts. The medium was removed and $100 \mu \mathrm{lof}$ MTT solution $(1 \mathrm{mg} / \mathrm{ml}$ in PBS) was added to each well of 96 multi-well plates and the plates were incubated for additional $3 \mathrm{hr}$ at $37^{\circ} \mathrm{C}$. Finally, $100 \mu 1$ of $10 \%$ (w/v) sodium dodecyl sulfate (SDS) in $0.01 \mathrm{~N} \mathrm{HCl}$ was added to each well and the absorbance was measured at $550 \mathrm{~nm}$ using the ELISA reader (Biotek System). Each concentration of plant extract was tested in hexaplicate and repeated twice in separate experiments. Percentage viability was calculated from the following relation:

$\%$ Viability $=\left[1-\mathrm{OD}_{\text {sample }} / \mathrm{OD}_{\text {control }}\right] \times 100$

\section{Results}

\section{DPPH radical assay}

Methanol (60\%) extract of thioproline was able to reduce the stable DPPH radical to the yellow-colored diphenylpicrylhydrazine (Figure 2). The lowest effect was observed in $0.1 \mathrm{mM}$ thioproline with $\sim 10 \%$ decoloration. Upto 73\% DPPH decoration was observed in case of $5.0 \mathrm{mM}$ thioproline.

\section{Hydroxyl radical scavenging}

When $60 \%$ methanol extract of Parkia timoriana seed was incubated with the reaction mixture used in the deoxyribose degradation assay, hydroxyl radicals were removed from the sugar and prevented its degradation. The seed extract at a concentration of $20 \mu \mathrm{g} / \mathrm{ml}$ could cause $\sim 20 \%$ scavenging of hydroxyl radicals, and up to $\sim 72 \%$ scavenging of hydroxyl radicals at $200 \mu \mathrm{g} / \mathrm{ml}$ concentration of the seed extract (Figure 3). 


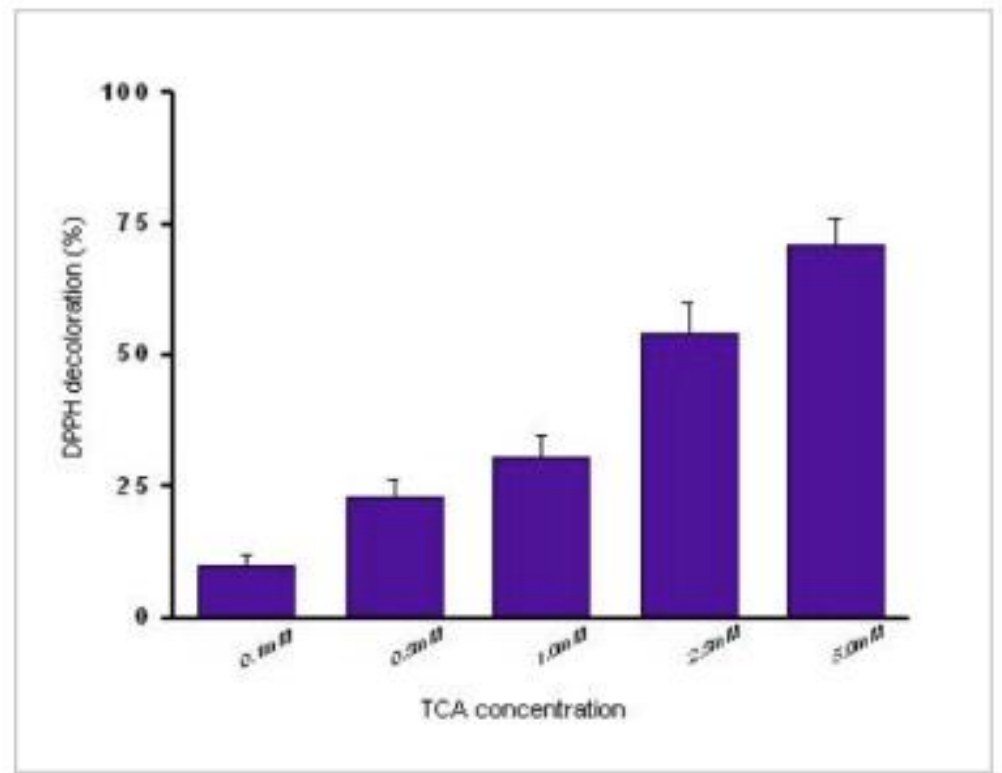

Figure 2: DPPH radical scavenging activity of thioproline

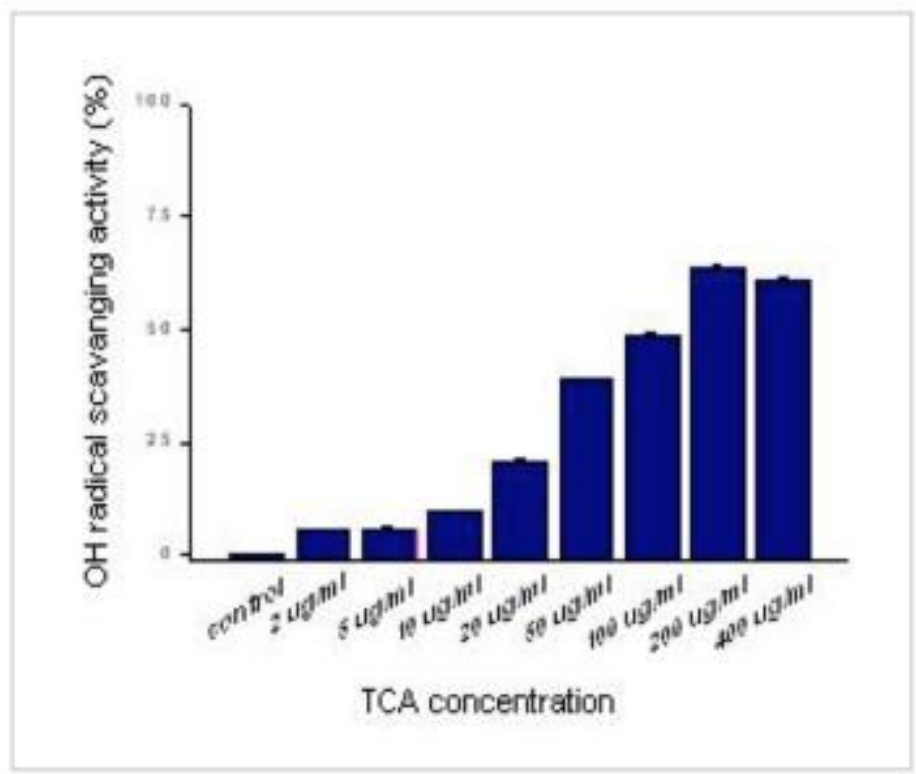

Figure 3: Hydroxyl radical scavenging activity of Parkia timoriana seed extract

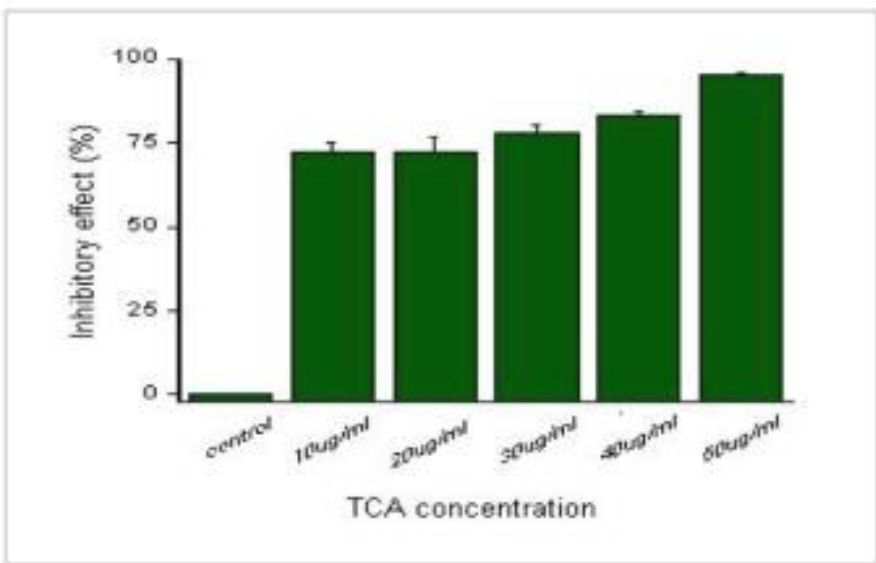

Figure 4: Inhibition of superoxide radical production by Parkia timoriana seed extract 


\section{Inhibition of superoxide radical}

Methanol extract of the seed extract was found to significantly scavenge the superoxide radicals generated from hypoxanthine/ xanthine oxidase system. There was gradual increase in the inhibition of superoxide radicals as the concentration of the seed extract increased from $10-50 \mu \mathrm{g} / \mathrm{ml}$ with the maximum inhibition of $\sim 98 \%$ at $50 \mu \mathrm{g} / \mathrm{ml}$ (Figure 4 ).

\section{Cytotoxicity test using MTT assay}

Methanol extract of Parkia timoriana seeds tested for cytotoxicity against mouse fibroblast cell line $\mathrm{NIH} / 3 \mathrm{~T} 3$ using standard MTT assay showed cell viability of $\sim 81 \%$ at $100 \mu \mathrm{g} / \mathrm{ml}$ gradually decreasing to $\sim 49 \%$ at $500 \mu \mathrm{g} / \mathrm{ml}$ showing that Parkia timotiana seed extracts could induce significant cytotoxicity.

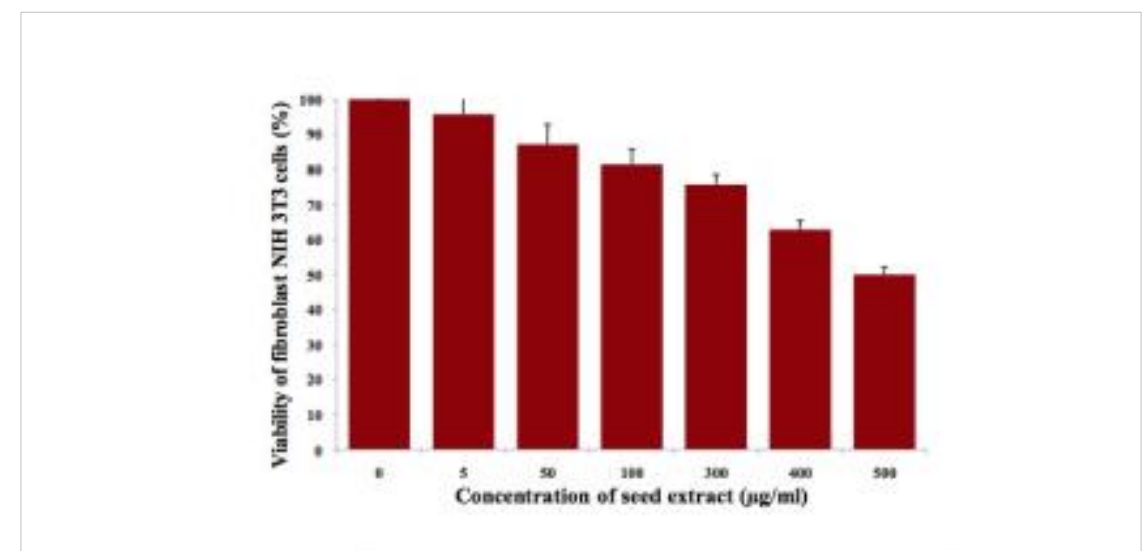

Fig:ure 5: Cytotoxicity testing by MTT assay of seed extract of Parkia timoriana

\section{Discussion}

Free radicals produced by metabolic processes endogenously or by environmental insults are deleterious to cellular targets like proteins, lipids, carbohydrates and DNA, and can alter cellular functions (Davies et al., 1987; Dezwart et al., 1999; Gebicki and Gebicki, 1999). Reactive oxygen species (ROS) are known to be carcinogens and act at various stages in neoplastic transformation (Cerutti, 1994). Permanent DNA sequence changes and rearrangements resulting into activation of proto-oncogenes or inactivation of tumor-suppressor genes may also be induced (Hsie et al., 1986; Moraes et al., 1990).

The body's antioxidant defense system comprises various antioxidants present in plasma or fluids in reduced state. While scavenging these reactive radical species, these are either oxidized or exhausted. Exogenously supplemented antioxidants can help in preventing oxidative damages by countering the reactive species or raising endogenous pool of antioxidants thereby strengthening the cellular defense system. Supplementation of dietary antioxidants of diversed types derived from plant-based resources enormously help in enhancing the body's own protective mechanism and thus serve as good preventive measures (Halliwell and Gutteridge, 1989; Wang et al., 1996). Phytochemicals possessing high antioxidant profiles have attracted attention for their possible application as anti-tumor agent, and also as protectant in radiation countermeasures (Paonam et al., 2013; Thokchom et al., 2014; Sharma, 2017). Such phytochemicals become all the more relevant particularly when they are edible and can be conveniently administered through dietary intakes as nutraceuticals.

Several medicinal plants contain bio-active molecules which are generally secondary metabolites possessing rich antioxidant properties. Besides, several non-conventional and under-utilized plant-based food largely consumed by people in north-east India are known to contain specific bio-active molecules which help in disease prevention. For instance, the tree bean is known to have very high content of the sulfur-containing molecule, thioproline which people have been consuming as delicacy since times immemorial. Simultaneously, people in the region also consume Shiitake mushroom which contains thioproline in high 
amount. Whether high thioproline intakes by the people have anything to do with the occurrence of low frequencies of stomach, intestinal and colorectal cancers require immediate attention. The present investigations reveal that thioproline is a potent antioxidant, and its cytotoxic property in mouse embryo fibroblast cell line makes it a candidate molecule of significant importance in drug development and pharmaceutical industry. This region within the Indo-Burmese mega-biodiversity 'hotspot' has a wide range of plant-based foods which are hitherto unknown to the rest of the world. Antioxidants of various kinds drawn from plant-based resources ultimately enter into the body through dietary intakes which finally help in sequestering the damaging oxyradicals, peroxyradicals and alkoxyradicals in cellular milieu rendering preventive beneficial effects and help cells protect from apoptotic and/or neoplastic transformation.

\section{Acknowledgement}

The author is thankful to the University Grants Commission, Government of India, New Delhi for financial support [Grant No. F. 18-1/ 2011 (BSR) dated 16 March 2015].

\section{References}

1. Brugarolas A and Gosalvez M: Treatment of cancer by an inducer of reverse transformation, Lancet 1(8159), 1980, 68-70.

2. Correa B, Blanco B, DelRio M, Victor V, Guayerbas N, Medina S and De la Fluente M: Effect of a diet supplemented with thioproline on murine macrophage function in a model of premature ageing, BioFactors 10(2-3), 1999, 195-200.

3. Cuendet M, Hostettmann $\mathrm{K}$ and Potterat $\mathrm{O}$ : Iridoid glucosides with free radical scavenging properties from Fragarea blumei, Helvetica Chimica Acta 80, 1997, 1144-1152.

4. Davies KJA, Delsingore ME and Lin SW: Protein damage in degradation of oxygen radicals, Journal of Biological Chemistry 262, 1987, 9902-9907.

5. Dezwart LL, Meerman JHN, Commandeur JNM and Vermenlen NPE: Biomarkers of free radical damage: applications in experimental animals and in humans, Free Radicals in Biology and Medicine 26, 1999, 202-206.

6. Gebicki S and Gebicki JM: Cross-linking of DNA and protein induced by hydroperoxides, Biochemical Journal 338, 1999, 629-636.

7. Halliwell B and Gutteridge JMC: Free Radicals in Biology and Medicine, Clarendon Press, Oxford, 1989.

8. Hsie A, Recio I, Katz D, Lee C, Wagner M and Schenley R: Evidence for reactive oxygen species inducing mutations in mammalian cells, Proceedings of National Academy of Sciences 83, 1986, 96109620.

9. Kunchandy E and Rao MNA: Oxygen radical scavenging activity of curcumin, International Journal of Pharmacognosy 58, 1990, 237-240.

10. Lee KW, Kundu JK, Kim SO, Chun K, Lee HJ and Surh Y: Cocoa polyphenols inhibit phorbol esterinduced superoxide anion formation in cultured HL-60 cells and expression of cyclooxygenase-2 and activation of NF- $\mathrm{kB}$ and MAPKs in mouse skin in vivo, Journal of Nutrition 136, 2006, 1150-1155.

11. Moraes EC, Keyse SM and Tyrell RM: Mutagenesis by hydrogen peroxide treatment of mammalian cells: a molecular basis, Carcinogenesis 11, 1990, 283-293.

12. Mossman TR: Rapid colorimetric assay for cellular growth and survival: application to proliferation and cytotoxicity assays, Journal of Immunological Methods 65(1-2), 1983, 55-63.

13. Okhawa $\mathrm{H}$, Ohoshi $\mathrm{N}$ and Yagi K: Assay of lipid peroxides in animal tissues by thiobarbituric acid reaction, Analytical Biochemistry 95, 1979, 351-358.

14. Paonam P, Thokchom DS and Sharma GJ: Free radical scavenging and antioxidant potentials of Panax pseudoginseng Wall., Journal of Free Radicals and Antioxidants 139, 2013, 289-294.

15. Sharma GJ: Tropical ginger extract as protectant in radiation countermeasures, Current Traditional Medicine 3, 2017, 000-000 [in press].

16. Tahira T, Ohgaki H, Wakabayashi K, Nagao M and Sugimura T: The inhibitory effect of thioproline on carcinogenesis induced by N-benzylmethylamine and nitrite, Food Chemistry and Toxicology 26(6), 1996, 511-516. 
17. Thokchom DS, Santikumar L and Sharma GJ: Protection of radiation-induced DNA damage in albino rats by Oroxylum indicum (L.) Vent., International Journal of Pharmacognosy and Phytochemical Research 6(3), 2014, 514-523.

18. Todaro GJ and Green H: Quantitative studies of the growth of mouse embryo cells in culture and their development into established cell lines, Journal of Cell Biology 17(2), 1963, 299-313.

19. Tsuda M and Kurashima Y: Food Factors for Cancer prevention, Springer-Verlag, Berlin, 1997.

20. Wang H, Cao D and Ronald PL: Total antioxidant capacity of fruits, Journal of Agricultural and Food Chemistry 44, 1996, 701-705. 


\title{
A two-step process for improving of refractory sulfide concentrate biooxidation
}

\author{
Maxim Muravyov ${ }^{1}$, Natalya Fomchenko ${ }^{2}$ \\ ${ }^{1}$ Institute of Microbiology, Research Center of Biotechnology of the Russian Academy of Sciences \\ Leninsky ave., 33/2, Moscow, Russia, maxmuravyov@gmail.com \\ ${ }^{2}$ Institute of Microbiology, Research Center of Biotechnology of the Russian Academy of Sciences \\ Leninsky ave., 33/2, Moscow, Russia, natalya.fomchenko@gmail.com
}

\begin{abstract}
In this study a method for improving the treatment efficiency of a refractory gold-bearing sulfide concentrate is proposed. This method consist of the oxidation of the concentrate through a two-step process. The first step is leaching with biogenic ferric iron at elevated temperature using the ferric iron-containing solution produced during the second step. The second step is biooxidation of the products of the first step by acidophilic chemolithotrophic microorganisms. A flotation concentrate, which contained pyrrhotite, arsenopyrite, pyrite, and antimonite, was used in the study. Comparison of the two-step and traditional (one-step) technologies was carried out and the flow sheet for the new process was proposed. Gold recovery from the sulfide concentrate by carbon-in-pulp cyanidation was $67.8 \%$ in the one-step process and $93.0 \%$ in the two-step process at 4 days of biooxidation, while it reached $82.4 \%$ and $94.1 \%$ in the one-step and two-step processes at 8 days of biooxidation, respectively. The proposed two-step process is a promising approach for enhancing the efficiency of gold recovery from sulfide concentrates by means of biooxidataion.
\end{abstract}

Keywords: biooxidation, acidophilic chemolitothrophic microorganisms, gold recovery, sulfide concentrate, ferric leaching

\section{Introduction}

Biooxidation of sulfide raw materials by acidophilic chemolithotrophic microorganisms is widely and successfully used in the industrial processes to extract non-ferrous and precious metals [1,2]. Sulfide oxidation by ferric ions is described by the following reaction:

$$
\mathrm{Me}_{\mathrm{n}} \mathrm{S}_{\mathrm{m}}+a n \mathrm{Fe}^{3+} \rightarrow n \mathrm{Me}^{\mathrm{a+}}+a n \mathrm{Fe}^{2+}+m \mathrm{~S}^{0}
$$

where Me is a metal, $a$ is its valency in the sulfide mineral, and $n$ and $m$ are stoichiometric coefficients.

In this process the role of microorganisms is limited to oxidation of ferrous ions and elemental sulfur according to the following reactions:

$$
\begin{gathered}
4 \mathrm{Fe}^{2+}+4 \mathrm{H}^{+}+\mathrm{O}_{2} \rightarrow 4 \mathrm{Fe}^{3+}+2 \mathrm{H}_{2} \mathrm{O} \\
2 \mathrm{~S}^{0}+3 \mathrm{O}_{2}+2 \mathrm{H}_{2} \mathrm{O} \rightarrow 2 \mathrm{H}_{2} \mathrm{SO}_{4}
\end{gathered}
$$

Acidophilic microorganisms that are able to oxidize sulfide minerals are phylogenetically heterogeneous and include representatives of several bacterial and archaeal phyla, such as mesophilic (Acidithiobacillus ferrooxidans, Leptospirillum ferrooxidans), thermotolerant (Leptospirillum ferriphilum, Ferroplasma acidiphilum, Acidiferrobacter thiooxydans), and moderately thermophilic species (At. caldus, Sulfobacillus spp., Acidimicrobium spp., and Acidiplasma spp.) [3]. Traditional processes of the tank biooxidation are characterized by the low oxidation rate and the significant retention time of sulfidic ore materials in bioreactors (4-6 days). Approach based on the division of the process into a high-temperature chemical step of leaching with biogenic ferric iron and a step of ferric iron bioregeneration with the use of microorganisms was proposed to intensify sulfide oxidation [4]. At the same time, conditions for the best process indices can be provided at every step. The goal of the present work was to develop the approaches to intensification of biooxidation of sulfidic concentrates. 


\section{Experimental}

Gold-bearing sulfide concentrate was used in the present work. The total content of iron sulfide (pyrrhotite) and arsenic sulfide (arsenopyrite) was up to $75 \%$. The concentrate contained $27.0 \% \mathrm{Fe}, 8.21 \% \mathrm{As}, 5.59 \% \mathrm{Sb}, 20.32 \% \mathrm{~S}$ and $108 \mathrm{~g} / \mathrm{t} \mathrm{Au}$. Leaching of the concentrate with biogenic ferric was conducted in a reactor that contained $1.0 \mathrm{~L}$ of pulp. The stirring rate was $440 \mathrm{rpm}$, and the temperature was maintained at $80{ }^{\circ} \mathrm{C}$ by heat exchangers connected to a thermostat. The leaching was conducted under batch conditions. The solid phase was loaded and mixed with the biologically generated $\mathrm{Fe}^{3+}$-containing solution; tests were conducted at a pulp density of $17 \%(\mathrm{w} / \mathrm{v})$. The liquid was preheated to the desired temperature with an initial $\mathrm{pH} 1.2$. The $\mathrm{pH}$ of the pulp was continuously monitored, and sulfuric acid (98.5\%) was added when necessary to maintain $\mathrm{pH}$ value in the range from 1.15 to 1.35 . The investigation of the biooxidation of the concentrate was conducted using two series of experiments: (a) a one-step process (with the original concentrate), (b) a two-step process (with the pre-leached concentrate). Experiments on the biooxidation of the concentrate were conducted in two bioreactors $(1.0 \mathrm{~L})$ that were connected in series under continuous conditions. A salt solution of the $9 \mathrm{~K}$ medium [5] without $\mathrm{Fe}^{2+}$ was used as the liquid phase. The medium was supplemented with yeast extract $(0.02 \% \mathrm{w} / \mathrm{v})$. A moderately thermophilic microbial consortium containing Sulfobacillus spp., Leptospirillum spp., and archaeal strains of Ferroplasma acidiphilum were used as an inoculum. The pulp density was maintained at $17 \%$ (w/v). The total residence time of the pulp in the two reactors was 8 days. The experiments were conducted at $39^{\circ} \mathrm{C}$ with an aeration of $4 \mathrm{~L} / \mathrm{min}$ and a stirring speed of $440 \mathrm{rpm}$. The $\mathrm{pH}$ of the pulp was monitored continuously and $\mathrm{H}_{2} \mathrm{SO}_{4}$ was added when necessary to maintain its values in the range from 1.5 to 1.9 .

\section{Results and discussion}

Under experimental conditions, the degree of sulfide oxidation in the leach residues after pre-leaching with biogenic ferric $\left(100 \mathrm{~min}, 80^{\circ} \mathrm{C}\right)$ was high: $64.3,31.1,27.1$, and $45.4 \%$ for iron, arsenic, antimony, and sulfur of all sulfide minerals, respectively. Thus, removal of the most easily oxidized components may be achieved at the step of leaching with biogenic ferric. One-step and two-step processes of concentrate biooxidation were carried out to determine the effect of ferric leaching of gold-bearing sulfide concentrate by means of a biosolution of ferric sulfate on the efficien-cy of subsequent biooxidation. The results of biooxidation of arsenopyrite concentrate in a one- and two-step processes, with subsequent gold recovery by cyanidation, are presented in Table 1. Biooxidation of the concentrate after leaching with biogenic ferric at $80{ }^{\circ} \mathrm{C}$ (two-step process) resulted in high arsenopyrite oxidation (92.8\%) in the first reactor, compared to $38.4 \%$ in the one-step process. Comparative analysis demonstrates that the oxidation levels for the major sulfidic elements are significantly higher in the two-step process (4 days residence time) than in the one-step process ( 8 days residence time). For example, at 4 days residence time (in the first reactor) in the two-step process, the oxidation level of arsenic was $54.4 \%$ higher than the level achieved in the one-step process at 8 days residence time (in the second reactor).

Table 1: Results of biooxidation and carbon-in-pulp cyanidation of the gold-bearing concentrate.

\begin{tabular}{|cccccc|}
\hline & $\begin{array}{c}\text { Unoxidized } \\
\text { concentrate }\end{array}$ & Two-step process & One-step process \\
\hline Total biooxidation time, days & - & 4 & 8 & 4 & 8 \\
\hline $\mathrm{Fe}_{\mathrm{s}}$ oxidation, \% & - & 79.3 & 89.2 & 60.4 & 71.1 \\
\hline $\mathrm{As}_{\mathrm{s}}$ oxidation, \% & - & 92.8 & 97.2 & 38.4 & 59.7 \\
\hline Gold recovery, \% & 57.0 & 93.0 & 94.1 & 67.8 & 82.4 \\
\hline
\end{tabular}

Gold recovery by cyanidation after 4 and 8 days was 67.8 and $82.4 \%$ for the one-step process and 93.0 and $94.1 \%$, respectively, for the two-step one. The proposed modification of existing technology makes it possible to utilize ferric sulfate produced during biooxidation, rather than wasting it. Supplementing the technology with pre-leach step using biogenic ferric was shown to result in 1.5-2 times faster oxidation of the concentrate. This will make it possible to decrease the volume of biooxidation reactor accordingly (1.5 to 2 times) and to improve gold recovery. A flow sheet for gold recovery from gold-bearing sulfide concentrates was proposed (Fig. 1). 


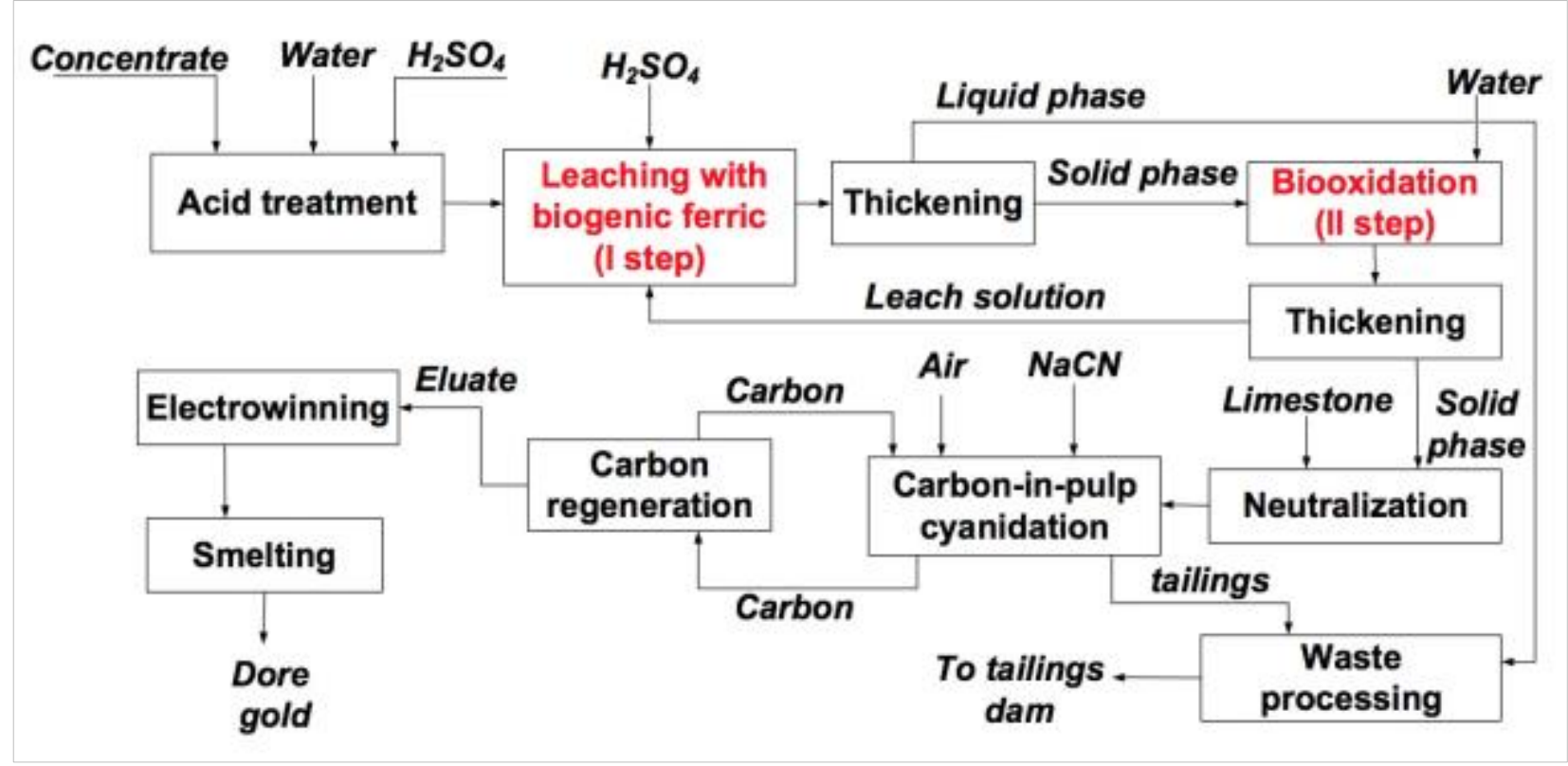

Fig. 1: Gold recovery from sulfide concentrate using a two-step process.

\section{Conclusion}

A two-step process for improving the treatment efficiency of a refractory gold-bearing sulfide concentrate is proposed. The first step is leaching with biogenic ferric iron at elevated temperature using the ferric iron-containing solution produced during the second step. The second step is biooxidation of the products of the first step by acidophilic chemolithotrophic microorganisms. This process allows to accelerate oxidation of sulfide minerals in gold-bearing concentrates and to decrease the duration of their biooxidation. The proposed two-step process is a promising approach for enhancing the efficiency of gold recovery from sulfide concentrates by means of biooxidataion.

\section{Acknowledgements}

This work was supported by the Russian Foundation for Basic Research, grant no. 15-08-03763_a.

\section{References}

1. H. R. Watling, "The bioleaching of sulphide minerals with emphasis on copper sulphides - A review," Hydrometallurgy, vol. 84, no. 1-2, pp. 81-108, 2006.

2. A. H. Kaksonen, B. M. Mudunuru, R. Hackl, "The role of microorganisms in gold processing and recovery - A review," Hydrometallurgy, vol. 142, pp. 70-83, 2014.

3. T. F. Kondrat'eva, T. A. Pivovarova, I. A. Tsaplina, N. V. Fomchenko, A. E. Zhuravleva, M. I. Murav'ev, V. S. Melamud, A. G. Bulayev, "Diversity of the communities of acidophilic chemolithotrophic microorganisms in natural and technogenic ecosystems," Microbiol., vol. 81, no. 4, pp. 3-27, 2012.

4. N. Smalley, G. Davis, "Operation of the Las Cruces ferric sulphate leach pilot plant," Miner. Eng., vol. 13, no. 6, pp. 599-608, 2000.

5. M. P Silverman, D. G. Lundgren, "Studies on the chemoautotrophic iron bacteria Ferrobacillus ferrooxidans. An improved medium and harvesting procedure for securing high yields," J. Bacteriol., vol. 77, pp. 642-647, 1959. 


\title{
Conceptual design of a self-sufficient hybrid biorefinery for syngas production and fermentation to ethanol
}

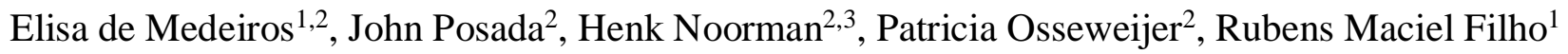 \\ ${ }^{1}$ University of Campinas (UNICAMP), School of Chemical Engineering, Av. Albert Einstein 500, Campinas, \\ Brazil \\ ${ }^{2}$ Delft University of Technology, Department of Biotechnology, Van der Maasweg 9, Delft, The Netherlands \\ ${ }^{3}$ DSM Biotechnology Center, Delft, The Netherlands
}

\begin{abstract}
Biorefineries are commonly classified according to conversion route as either biochemical or thermochemical. A third platform, currently at an earlier stage of development, consists of a hybrid route incorporating both conversion types in sequence. The present study explores a possible arrangement of hybrid biorefinery for the production of bioethanol from biomass residues, specifically sugarcane bagasse from Brazilian sugar-mills. The design comprises indirectly-heated biomass gasification followed by syngas fermentation to ethanol and includes units of heat recovery and power generation to ensure energy self-sufficiency in the integrated plant. Syngas fermentation, a relatively novel technology, is performed by autotrophic, anaerobic bacteria that metabolize $\mathrm{CO} / \mathrm{H}_{2} / \mathrm{CO}_{2}$ via acetogenic pathway. The resulting broth is highly dilute (aprox. $2.0 \mathrm{wt} \%$ ethanol), therefore ethanol purification is enhanced with heat-integrated multi-effect distillation to reduce energy expenses. In the present study, a possible, non-optimal flowsheet was first simulated in the commercial software Aspen Plus, applying design concepts and chemical engineering heuristic rules, with necessary adjustments to make it energetically self-sufficient. In a parallel study on syngas fermentation metabolism using Flux Balance Analysis, it was observed that syngas composition greatly affects ethanol to acetate selectivity, meaning it is a main project parameter that must be optimized concurrently with others, such as gasification temperature and distillation conditions. Due to the high number of parameters entangled in the complex flowsheet, the latter was optimized using a surrogate-model approach and multi-objective genetic algorithm, which are explained in this work. The proposed method enabled finding an optimal solution with $40 \%$ of carbon conversion to ethanol, while still maintaining energy self-sufficiency, against the initial result of $30 \%$ that was obtained with the non-optimal flowsheet simulated in Aspen Plus.
\end{abstract}

Keywords: biofuels, lignocellulosic ethanol, biomass gasification, syngas fermentation

\section{Introduction}

The past decades have seen a huge increase in the production of ethanol, a renewable, clean burning and high-octane biofuel with the potential to reduce oil dependency and carbon emissions. Currently commercialized ethanol is, however, mostly derived from first generation ( $1^{\text {st }}$-Gen) feedstocks, i.e. food crops such as sugarcane and corn starch, thus raising other social and environmental issues: threat of food insecurity due to diversion of crops, soil degradation and biodiversity loss due to expansion of intensive agriculture, besides other environmental problems associated with the use of fertilizers, such as eutrophication and nitrous oxide emissions. The use of non-food crops, termed second-generation $\left(2^{\text {nd }}-G e n\right)$ feedstocks, such as sugarcane bagasse, grasses and corn stover, has then been widely investigated, although currently produced $2^{\text {nd }}-G e n$ ethanol is hardly competitive with its $1^{\text {st }}-$ Gen counterpart, even with several demonstration and commercial scale plants having been put into operation in the last decade [1].

Currently, two main conversion platforms are considered for the production of ethanol from $2^{\text {nd }}-$ Gen feedstocks: $(i)$ the biochemical platform, which employs the fermentation of sugars obtained from acid or enzymatic hydrolysis of biomass; and (ii) the thermochemical platform, where syngas is produced from biomass through gasification and then it is converted to ethanol, traditionally via chemical catalysis. A possible pathway integrates both concepts by combining biomass gasification with further conversion of syngas via fermentation with specific bacteria, called acetogens, that are capable of metabolizing $\mathrm{CO}, \mathrm{H}_{2}$ and $\mathrm{CO}_{2}$ into cell mass, acetate and ethanol. While the gasification-fermentation (GF) hybrid route has been demonstrated by a few companies, its actual competitiveness 
remains uncertain due to its novelty character. Nonetheless, recent journal articles estimate production cost, ethanol yield and carbon conversion that are comparable to other $2^{\text {nd }}-$ Gen pathways $[2,3]$.

The present study is concerned with evaluating the highest possible carbon conversion from biomass to ethanol that could be achieved with a proposed, energy self-sufficient, arrangement of the GF route, by simultaneous optimization of operational parameters that are linked in the process flowsheet. A previous study published by our group [2], which presented techno-economic results for a preliminary, non-optimal, flowsheet was used as source for the base flowsheet to be optimized, which is explained in Sec. 2 of this paper. In Sec. 3, syngas fermentation is explored using the genome-scale reconstruction of Clostridium ljungdahlii, a wild-type acetogen, and the in silico tool of Flux Balance Analysis. Finally, the methods and results for the process flowsheet optimization are exposed in Sec. 4.

\section{Process Design and Simulation}

In a previous work, a possible flowsheet for the GF route was simulated using commercial simulator Aspen Plus, with appropriate choices of physical property methods and thermodynamic models. The methodology and results for this case are thoroughly explained in [2]. The present work considers the same process structure, consisting of the following main process units, represented in Fig. 1: (i) biomass drying and gasification in a dual fluidized bed (indirectly-heated) gasifier; (ii) heat recovery from hot syngas and flue gas; (iii) power generation from syngas in a combined Brayton/Rankine cycle; (iv) syngas fermentation; and (v) ethanol purification using multi-effect distillation. This flowsheet was tuned to assure energy self-sufficiency, i.e. that steam and power requirements for the whole process were met with the outcomes from heat recovery and power units. The units are generally described next:

(i.a) sugarcane bagasse entering the process with $50 \%$ of moisture (biomass composition is provided in [2]) is dried using hot flue gases from the gasifier;

(i.b) the indirectly-heated gasifier comprises two distinct, inter-connected, fluidized beds, namely a gasification zone bed, where biomass reacts with steam in a reducing environment to produce syngas (mostly $\mathrm{CO}, \mathrm{H}_{2}$ and $\mathrm{CO}_{2}$ ), besides char, and a combustion zone bed, where char, which is essentially carbon, undergoes combustion with excess air, producing flue gas $\left(\mathrm{CO}_{2}, \mathrm{~N}_{2}, \mathrm{O}_{2}\right)$ and heat for the endothermic gasification reactions;

(ii) heat is recovered from hot gases to produce process steam (e.g. syngas leaves the gasifier at temperatures around $800-900{ }^{\circ} \mathrm{C}$, whereas it is fed to the bioreactor and to the gas turbine at less than $40{ }^{\circ} \mathrm{C}$ );

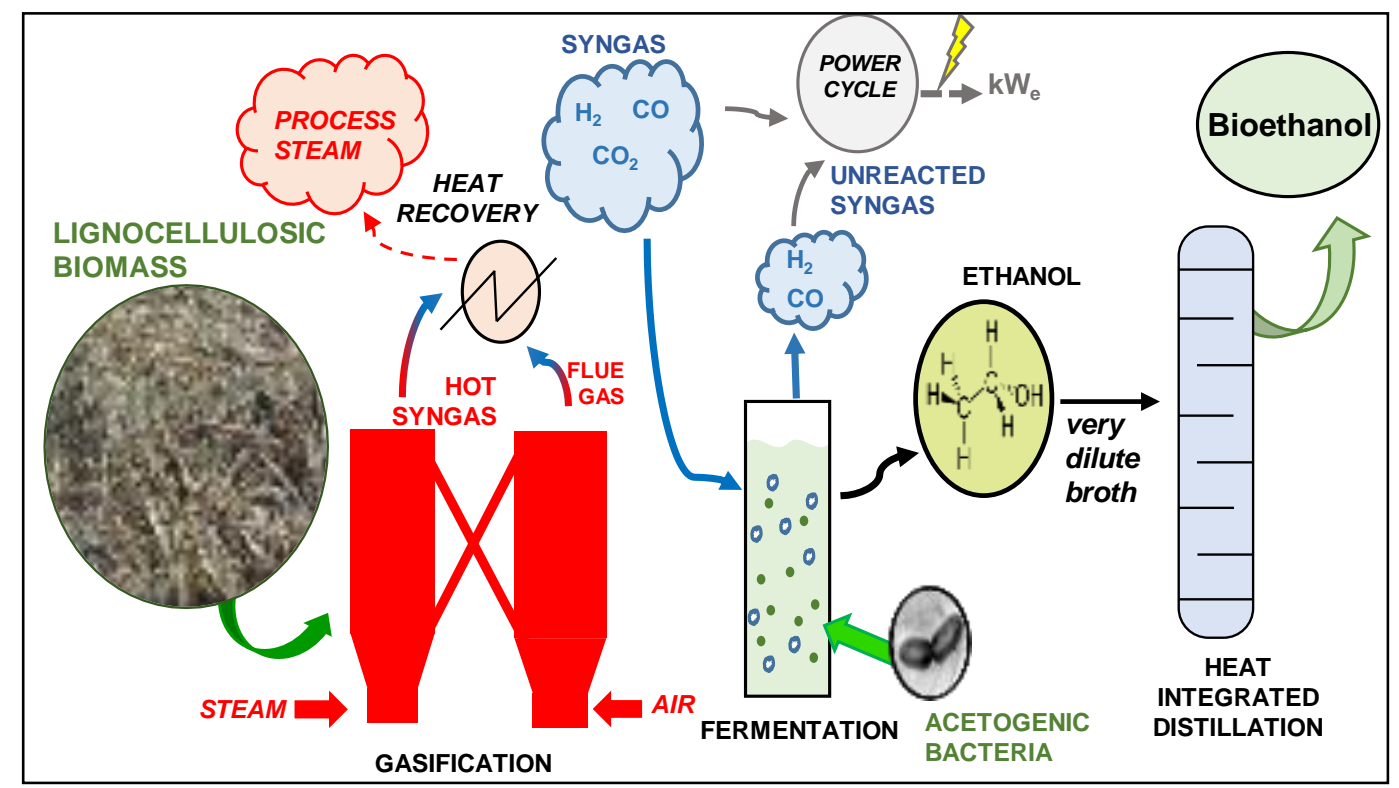

Fig. 1: Conceptual design of ethanol production through hybrid gasification-fermentation route.

(iii) the power unit consists of a gas turbine (Brayton cycle) fed with unreacted syngas from fermentation (i.e. the bioreactor off-gas) and/or part of the syngas from the gasifier, and a steam turbine (Rankine cycle) run with steam produced from the residual heat available in the flue gas from the gas turbine; 
(iv) syngas fermentation assumes the use of the bacteria Clostridium ljungdahlii at $37{ }^{\circ} \mathrm{C}$ and atmospheric pressure in conditions of residence time and gas conversions similar to those reported by [4];

$(v)$ in order to reduce energy expenses required to concentrate ethanol from $\sim 2 \mathrm{wt} \%$ to $\sim 94 \mathrm{wt} \%$, this study proposes the use of a multi-effect distillation arrangement with three heat-integrated columns as a preconcentration step and a fourth column to achieve the final composition.

Multi-effect distillation (MED) cuts energy expenses by linking the condenser of a higher-pressure column with the reboiler of a lower-pressure column, hence allowing for heat to be recovered [5]. In the proposed configuration, the dilute feed stream is divided into three streams that are fed to three distillation columns operating under different pressures, in such a way that the overall reboiler duty required to concentrate the feed stream is significantly reduced as two of the columns have their reboiler duty provided by the adjacent higher-pressure column. In the preliminary study presented in [2], the three pressures were assumed to be 6, 3 and 1 bar, with the final column also operating under atmospheric pressure. In the present study, however, the operating pressures are part of the optimization parameters.

Despite non-optimal, this flowsheet led to reasonable results: an overall carbon conversion of $30 \%$, which is very similar to other $2^{\text {nd }}$-Gen conversion routes, and a minimum ethanol selling price of 0.78 US $\$ / L$ (2016) considering high uncertainties in CAPEX and raw materials costs [2], which, although being more expensive than ethanol market price, is comparable to estimates made for $2^{\text {nd }}-$ Gen ethanol from other types of conversion routes.

\section{3. in silico Analysis of Clostridium ljungdahlii Metabolism}

Flux Balance Analysis (FBA) is a common computational method used to evaluate metabolic fluxes within a metabolic network. It is essentially a linear programming problem where a linear system with more columns than rows (i.e. with infinite solutions) is solved for the optimization of an objective function such as maximizing biomass growth, given a set of constraints for lower and upper bounds for the distinct fluxes. In the present study, the genomescale reconstruction of Clostridium ljungdahlii published by [6] was used as source of the stoichiometric matrix, i.e. the matrix containing all metabolites in rows (698 in total) and reaction stoichiometric coefficients in columns (785 in total).

FBA was conducted using COBRA Toolbox [7] in MATLAB environment in order to evaluate the effects of varying the uptake rates of $\mathrm{H}_{2}$ and $\mathrm{CO}$ on the formation of fermentation products (acetate and ethanol), which are affected by the redox balance in the Wood-Ljungdahl pathway. Fig. 2 depicts how ethanol and acetate production rates would

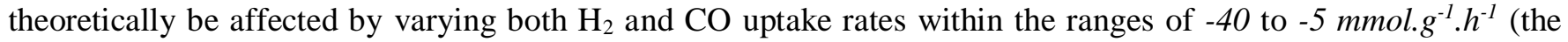
negative sign is assigned to molecules that are consumed), where the diagonal dashed lines indicate the $\mathrm{H}_{2} / \mathrm{CO}$ mole ratios, with the area above the main diagonal representing the conditions with $\mathrm{H}_{2} / \mathrm{CO}>1$.

As syngas composition (and the $\mathrm{H}_{2} / \mathrm{CO}$ ratio) can be adjusted by gasification conditions (steam to biomass ratio, temperature etc), or with the use of an additional water-gas shift reactor, this analysis can provide insights into how the different process parameters can be tuned altogether to improve the overall process outcome. It is clear from Fig. 2 that ethanol production is enhanced with higher $\mathrm{H}_{2} / \mathrm{CO}$ ratios, which is due to the fact that excess $\mathrm{H}_{2}$ allows for the build-up of reducing agent $\mathrm{NAD}(\mathrm{P}) \mathrm{H}$ as $\mathrm{H}_{2}$ is oxidized via hydrogenase, according to the ferredoxin $N A D P H$ linked hydrogenase reaction that is present in the genome-scale reconstruction used in this study (Eq. 1). The resulting excess $\mathrm{NAD}(\mathrm{P}) \mathrm{H}$, which must be re-oxidized, thus leads to the reduction of acetate to ethanol, via ferredoxin-NADP reductase (Eq. 2), acetaldehyde ferredoxin oxireductase (Eq. 3) and alcohol dehydrogenase (Eq. 4) enzyme reactions.

$$
\begin{gathered}
\mathrm{Fd}_{\text {ox }}+2 \mathrm{H}_{2}+\mathrm{NADP^{+ }} \leftrightarrow \mathrm{Fd}_{\text {red }}+3 \mathrm{H}^{+}+\mathrm{NADPH} \\
\mathrm{Fd}_{\text {ox }}+\mathrm{NAD}^{+}+2 \mathrm{NADPH} \leftrightarrow \mathrm{Fd}_{\text {red }}+\mathrm{H}^{+}+\mathrm{NADH}+2 \mathrm{NADP} \mathrm{P}^{+} \\
\mathrm{CH}_{3} \mathrm{COO}^{-}+\mathrm{Fd}_{\text {red }}+3 \mathrm{H}^{+} \leftrightarrow \mathrm{CH}_{3} \mathrm{CHO}+\mathrm{Fd}_{\text {ox }}+\mathrm{H}_{2} \mathrm{O} \\
\mathrm{CH}_{3} \mathrm{CHO}+\mathrm{NADH} \leftrightarrow \mathrm{C}_{2} \mathrm{H}_{6} \mathrm{O}+\mathrm{NAD}^{+}
\end{gathered}
$$

It is worth noting that, while this is a possible way of increasing ethanol to acetate selectivity, it does not mean that ethanol formation is precluded when $\mathrm{H}_{2} / C O<1$. As a matter of fact, several authors have reported ethanol formation 
for lower $\mathrm{H}_{2} / \mathrm{CO}$ ratios, for example [8], which used $\mathrm{H}_{2} / \mathrm{CO}=0.36$. Other factors would affect the results similarly, for example: limited supply of certain nutrients and the presence of acetic acid in the external environment under low $\mathrm{pH}$ are known to promote the shift from acidogenesis to solventogenesis $[4,9]$.
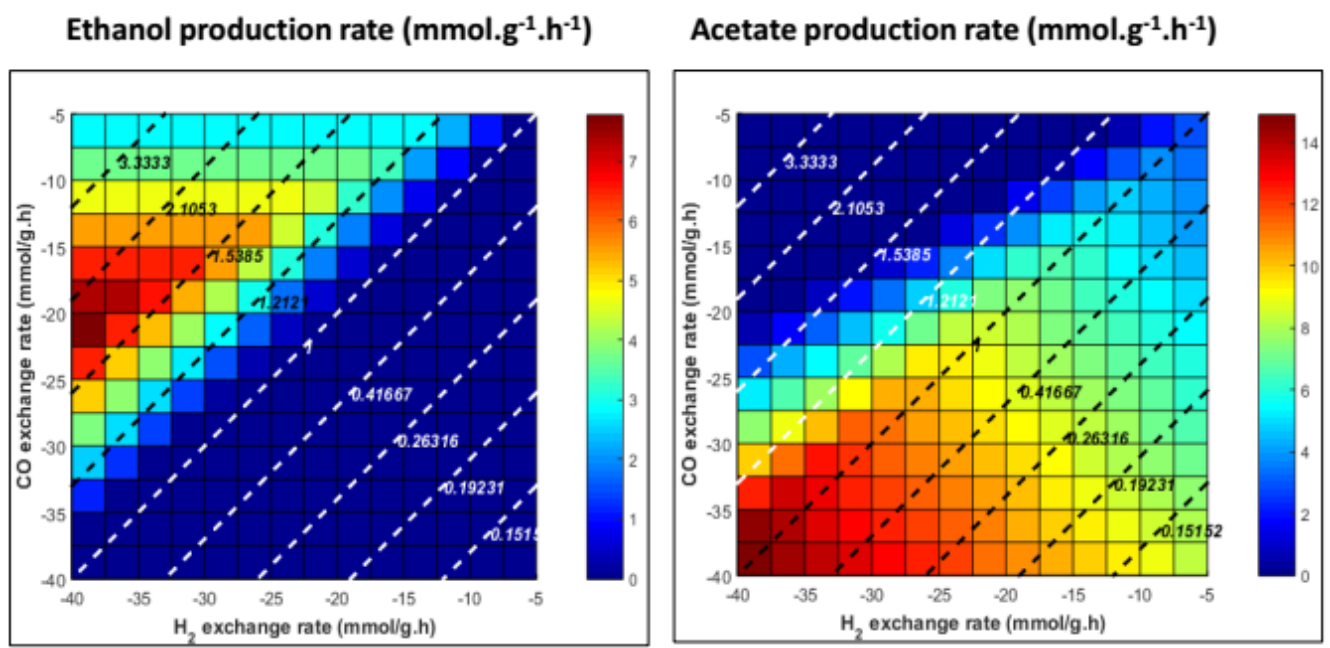

Fig. 2: Ethanol and acetate production rates predicted with Flux Balance Analysis of $\mathrm{CO} / \mathrm{H}_{2}$ fermentation by Clostridium ljungdahlii.

\section{Multi-objective Optimization Using Surrogate Models}

While gasification and syngas fermentation are the core units of the GF route, they shouldn't be optimized separately from the others. For illustration, changing gasification conditions to improve ethanol productivity in the bioreactor also changes energy requirements for the gasifier, which in turn means that more syngas should be diverted to the production of heat rather than ethanol. Meanwhile, different broth compositions would lead to different optimal configurations of the distillation columns, leading to different energy requirements and, consequently, different proportions of syngas that must be diverted. In the present study, the most relevant parameters that were simultaneously optimized are: (i) gasifier temperature; (ii) steam to biomass ratio in the gasifier; (iii) air excess in the combustion zone of the gasifier; (iv) fraction of produced syngas that is fed to the bioreactor (the remaining being sent to power generation); $(v)$ pressure in the high-pressure column from the multi-effect distillation arrangement (the other pressures are tied to this one); (vi) molar reflux ratio in the high-pressure column from the multi-effect distillation arrangement; (vii) molar boil-up ratio in the fourth distillation column.

Since the flowsheet is a complex structure with many interconnections and it is simulated in Aspen Plus using rigorous models for chemical and phase equilibrium, it lacks the robustness required to vary different block specifications at the same time without leading to convergence problems, making it impossible to be optimized directly in Aspen. For this reason, the nonlinear optimization problem was built in MATLAB using surrogate, reduced-order, models and solved using a metaheuristic method, namely a genetic algorithm, as explained in Sec. 4.1 and 4.2 , respectively.

\subsection{Construction of Unit Operation Surrogate Models}

Surrogate models are simplified, yet accurate, models that substitute rigorous models in order to reduce the complexity of the mathematical problem. In the present study, surrogate models were obtained by fitting process data (generated with rigorous models in Aspen Plus) to simple quadratic equations represented by Eq. 5, where $\beta_{0}$ is the intercept, $\beta_{i}$ are the coefficients for the linear terms of the input variables $x_{i}, \beta_{i i}$ are the coefficients for the quadratic terms and $\beta_{i j}$ are the coefficients for the interaction terms between two different input variables $x_{i}$ and $x_{j}$. Response variables include, but are not limited to: $\mathrm{CO}, \mathrm{H}_{2}$ and $\mathrm{CO}_{2}$ yields $\left(\mathrm{Nm}^{3} / \mathrm{kg}\right.$ dry biomass) in the gasifier, ethanol mass fraction in the broth, broth yield ( $\mathrm{kg}$ broth $/ \mathrm{Nm}^{3}$ syngas), bioreactor cooling requirements ( $\mathrm{kW} / \mathrm{Nm}^{3}$ syngas), ethanol mass fraction in the top products from the multiple distillation columns, reboiler duty of first column from the multieffect arrangement, physical properties such as temperature and heat capacity of various streams, etc. 


$$
\hat{y}(\boldsymbol{x})=\beta_{0}+\sum_{i=1}^{n} \beta_{i} \cdot x_{i}+\sum_{i=1}^{n} \beta_{i i} \cdot x_{i}{ }^{2}+\sum_{i=1}^{n} \sum_{j \geq i}^{n} \beta_{i j} \cdot x_{i} \cdot x_{j}
$$

Surrogate models can be used to generate response surfaces in order to visualize the effects exerted by the input variables in pairs. For example, the predictor equation for the ethanol mass fraction in the broth as function of the syngas composition (Eq. 6), considering only significant predictor terms, was used to generate the response surface depicted in Fig. 3, where the two variables $x_{1}$ and $x_{2}$ correspond to $y_{\mathrm{CO}}$ and $y_{\mathrm{H} 2} /\left(y_{\mathrm{CO}}+y_{\mathrm{CO} 2}\right)$, respectively.

$$
\hat{y}(\boldsymbol{x})=0.0169+0.0044 x_{1}+0.0038 x_{2}-0.0011 x_{2}{ }^{2}
$$

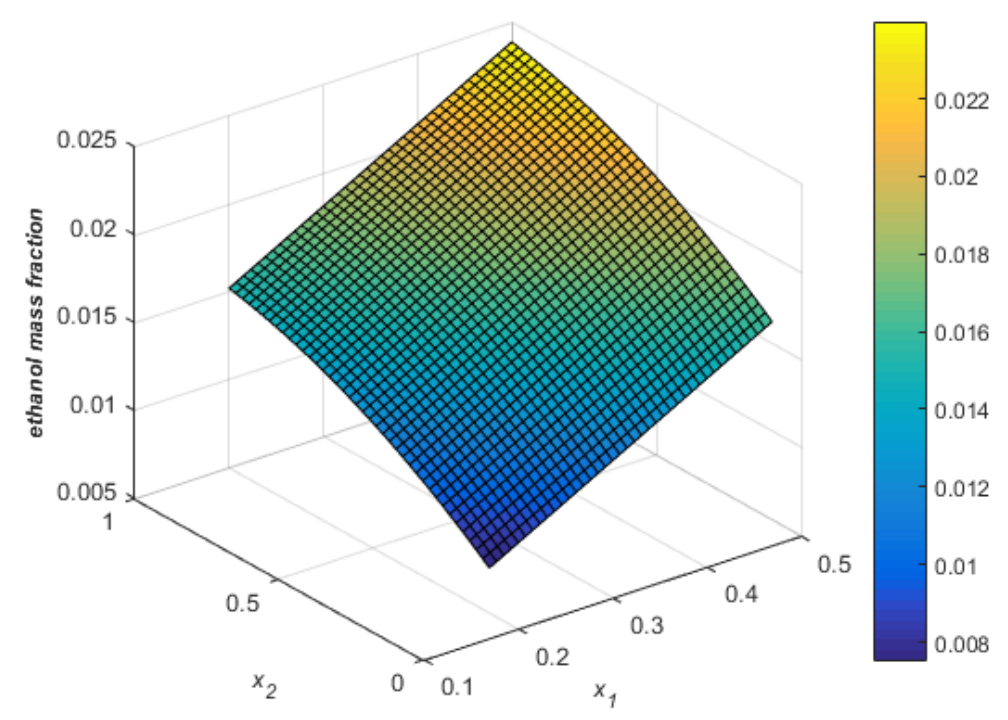

Fig. 3: Response surface for ethanol mass fraction in the broth as function of syngas composition. $\left(x_{1}=y_{C O} ; x_{2}=\right.$ $y_{\mathrm{H} 2} /\left(y_{\mathrm{CO}}+y_{\mathrm{CO} 2}\right)$, where $y_{\mathrm{CO}}, y_{\mathrm{H} 2}, y_{\mathrm{CO} 2}$ are the mole fractions of $\mathrm{CO}, \mathrm{H}_{2}$ and $\mathrm{CO}_{2}$ in syngas).

\subsection{Multi-objective Genetic Algorithm Optimization}

The flowsheet superstructure containing surrogate models as functions of the input variables was optimized with regard to two distinct objectives, thus making it a multi-objective problem: (i) minimizing the steam deficit, i.e. the amount of steam required by the process minus the amount of steam that is produced in the process; and (ii) maximizing the carbon conversion (\%) from biomass to ethanol. As the objective functions must be provided as minimization functions, the objective (ii) is actually minimizing the negative value of the carbon conversion. The genetic algorithm function in MATLAB was used to generate the Pareto Front depicted in Fig. 4, which contains the optimal points for which it would be impossible to improve one of the objectives without negatively affecting the other. It is, therefore, a trade-off problem for which the ultimate decision regarding the best result is made by the human designer. In this case, as energy self-sufficiency is one of the main goals of the present study, it is clear from Fig. 4 that the best result would be for carbon conversion values around 40\%, where the steam deficit is still roughly zero. Table 1 presents the most relevant parameter values under optimal conditions.

Table 1: Main optimal parameter values for ethanol production via GF route.

\begin{tabular}{|c|c|c|c|c|c|c|}
\hline (i) & $($ ii $)$ & $($ iii) & $($ iv $)$ & $(v)$ & (vi) & (vii) \\
\hline $\begin{array}{c}\text { gasifier } \\
\text { temperature } \\
\text { gasification } \\
\text { zone) }\end{array}$ & $\begin{array}{c}\text { steam to } \\
\text { biomass ratio } \\
\text { in the gasifier }\end{array}$ & $\begin{array}{c}\text { air excess in } \\
\text { gasifier } \\
\text { combustion } \\
\text { zone }\end{array}$ & $\begin{array}{c}\text { fraction of } \\
\text { produced } \\
\text { syngas fed to } \\
\text { bioreactor }\end{array}$ & $\begin{array}{c}\text { pressure at the } \\
\text { bottom of the } \\
\text { first column }\end{array}$ & $\begin{array}{c}\text { molar reflux } \\
\text { ratio in first } \\
\text { column }\end{array}$ & $\begin{array}{c}\text { molar boil-up } \\
\text { ratio in final } \\
\text { column }\end{array}$ \\
\hline $800^{\circ} \mathrm{C}$ & 0.15 & $16 \%$ & 0.96 & 2.3 bar & 0.12 & 0.31 \\
\hline
\end{tabular}




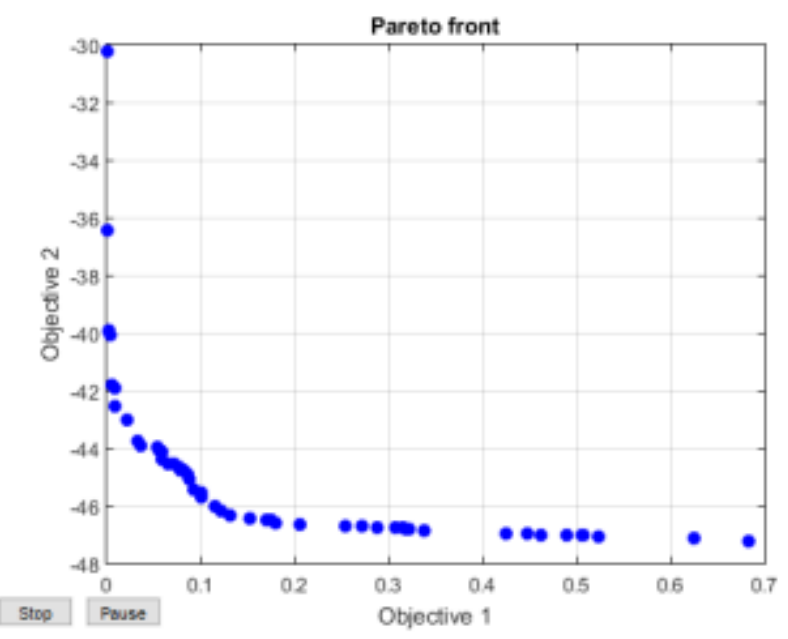

Fig. 4: Pareto Front obtained with multi-objective genetic algorithm optimization for ethanol production via GF route. (Objective 1: $\mathrm{kg}$ steam required - $\mathrm{kg}$ steam produced per kg biomass; Objective 2: - \% carbon converted to ethanol).

\section{Conclusions}

The gasification-fermentation (GF) route is one of the pathways for production of $2^{\text {nd }}$-Gen biofuels being investigated by researchers in academia and industry. Like other pathways, it presents its own set of technical challenges and advantages. The present study presented a conceptual flowsheet for ethanol production from sugarcane bagasse via GF route and explored the possibilities of improving process performance with regard to overall carbon conversion and energy self-sufficiency by simultaneously optimizing various process parameters. While it was observed through Flux Balance Analysis that syngas composition is a main parameter affecting ethanol formation, gasification conditions, split fractions of syngas diverted for heat and power systems, and distillation conditions, among other parameters, were optimized using a genetic algorithm for the multi-objective optimization of the nonlinear system of equations generated with the surrogate models. The results indicate that the process could achieve carbon conversion as high as $40 \%$ while maintaining energy self-sufficiency, whereas $2^{\text {nd }}-$ Gen conversion processes are commonly reported to achieve around $30 \%$ of overall carbon conversion.

\section{Acknowledgements}

The authors acknowledge DSM and BE-Basic Foundation for financial support. This work is carried out as part of a Dual Degree PhD project under the agreement between UNICAMP and TU-DELFT.

\section{References}

1. A. Koukoulas. (2016, December 12). A Critical Look at Cellulosic Ethanol and Other Advanced Biofuels. Biofuels Digest [Online]. Available: http://www.biofuelsdigest.com/bdigest/2016/12/12/a-critical-look-atcellulosic-ethanol-and-other-advanced-biofuels/

2. E. M. de Medeiros, J. A. Posada, H. Noorman, P. Osseweijer, R. Maciel Filho, "Hydrous bioethanol production from sugarcane bagasse via energy self-sufficient gasification-fermentation hybrid route: simulation and financial analysis," J. Clean. Prod., 2017.

3. P. Roy, A. Dutta, B. Deen, "Greenhouse gas emissions and production cost of ethanol produced from biosyngas fermentation process," Bioresource Technol., vol. 192, pp. 185-191, 2015.

4. J. L. Gaddy, D. K. Arora, C. -W. Ko, J. R. Phillips, R. Basu, C. V. Wikstrom, E. C. Clausen, "Methods for increasing the production of ethanol from microbial fermentation", U.S. Patent 7,285,402 B2, 2007.

5. B. Linnhoff, H. Dunford, R. Smith, "Heat integration of distillation columns into overall processes," Chem. Eng. Sci., vol. 38, pp. 1175-1188, 1983.

6. H. Nagarajan, M. Sahin, J. Nogales, H. Latif, D. R. Lovley, A. Ebrahim, K. Zengler, "Characterizing acetogenic metabolism using a genome-scale metabolic reconstruction of Clostridium ljungdahlii," Microb. Cell Fact., vol. 12, pp. 1-13, 2013.

7. S. A. Becker, A. M. Feist, M. L. Mo, G. Hannum, B. Ø Palsson, M. J. Herrgard, "Quantitative prediction of cellular metabolism with constraint-based models: the COBRA Toolbox," Nat. Protoc., vol. 2, no. 3, pp. 727-738, 2007. 
8. H. Younesi, G. Najafpour, A. R. Mohamed, "Ethanol and acetate production from synthesis gas via fermentation processes using anaerobic bacterium Clostridium ljungdahlii," Biochem. Eng., vol. 27, pp. 110$119,2005$.

9. H. N. Abubackar, F. R. Bengelsdorf, P. Dürre, M. C. Veiga, C. Kennes, "Improved operating strategy for continuous fermentation of carbon monoxide to fuel-ethanol by clostridia," Appl. Energ., vol. 169, pp. 210217, 2016. 